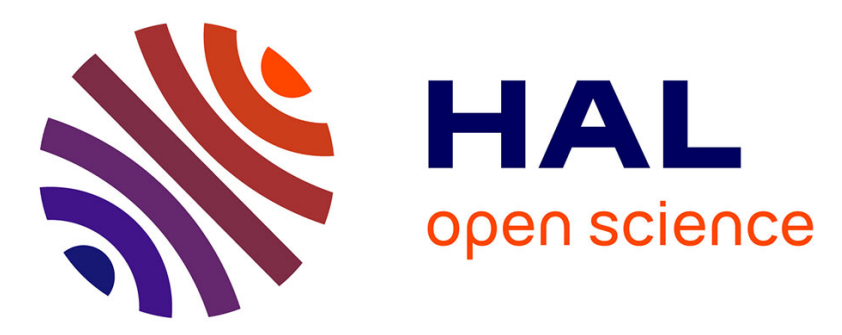

\title{
A self-contained composition space solution method for strained and curved premixed flamelets
} Arne Scholtissek, Pascale Domingo, Luc Vervisch, Christian Hasse

\section{To cite this version:}

Arne Scholtissek, Pascale Domingo, Luc Vervisch, Christian Hasse. A self-contained composition space solution method for strained and curved premixed flamelets. Combustion and Flame, 2019, 207, pp.342-355. 10.1016/j.combustflame.2019.06.010 . hal-02313894

HAL Id: hal-02313894

https://hal-normandie-univ.archives-ouvertes.fr/hal-02313894

Submitted on 4 Dec 2020

HAL is a multi-disciplinary open access archive for the deposit and dissemination of scientific research documents, whether they are published or not. The documents may come from teaching and research institutions in France or abroad, or from public or private research centers.
L'archive ouverte pluridisciplinaire HAL, est destinée au dépôt et à la diffusion de documents scientifiques de niveau recherche, publiés ou non, émanant des établissements d'enseignement et de recherche français ou étrangers, des laboratoires publics ou privés. 


\title{
A self-contained composition space solution method for strained and curved premixed flamelets
}

\author{
A. Scholtissek ${ }^{a, *}$, P. Domingo ${ }^{b}$, L. Vervisch ${ }^{\mathrm{b}}$, C. Hasse $^{\mathrm{a}}$ \\ ${ }^{a}$ Institute for Simulation of reactive Thermo-Fluid Systems, TU Darmstadt, Otto-Berndt-Straße 2, 64287 \\ Darmstadt, Germany \\ ${ }^{b}$ CORIA - CNRS, Normandie Université, INSA de Rouen, Technopôle du Madrillet, BP 8, 76801 \\ Saint-Étienne-du-Rouvray, France
}

\begin{abstract}
Solving flames in scalar or composition space usually requires the modeling of scalar dissipation rates, or scalar gradients, which appear in the Jacobian of the transformation from the physical-space coordinates to the scalar space coordinates attached to the flame surface. Recently, Scholtissek et al. (2019) have discussed a self-contained solution for freely propagating premixed flames, in which the gradient distribution of the coordinate is also solved in scalar space. This approach is here extended to include curvature, strain and effects of unsteadiness. The resulting method is applied to a constant pressure and homogeneous ignition case, a stagnation flame, a tubular flame and a spherical expanding flame, capturing accurately effects of unsteadiness, strain and curvature. The results are systematically validated against physical-space solutions and experiments. In addition to the possibility of exploring these various canonical problems with a single set of equations, it is shown that another major outcome of this new formulation lies in the possibility of studying steady flames subjected to negative strain.
\end{abstract}

Keywords: premixed flamelet, progress variable space, strain, curvature, gradient equation

\footnotetext{
${ }^{*}$ Corresponding author:

Email address: scholtissek@stfs.tu-darmstadt.de (A. Scholtissek)
} 


\section{Introduction}

In most combustion systems the fraction of the flow occupied by the reaction zones stays very small. The characteristic thicknesses over which intermediate radical chemical species evolve are orders of magnitude smaller than the characteristic length of the large-scale flow motion, which carries the turbulence kinetic energy driving the mixing of the reactants. To deal with this strong multi-scale character of combustion physics [1], scalar or composition space coordinates attached to the flame surface are usually introduced, to analyse results of both experiments and simulations [2].

Such scalar space coordinates were first designed for conveniently focussing theoretical analyses on the molecular diffusion layers feeding the thin reaction zones in laminar diffusion flames [3]. Then, scalar coordinate systems have been used systematically in flame theory, up to fuel-spray flames 4]. Composition or scalar space coordinates were also introduced for turbulent combustion modeling, in diffusion flamelets [5, 6], in premixed flamelets [7] 9], in conditional moment closure (CMC) [10] or again in the transport of probability density functions (PDF) [11-13]. Even though the underlying physical hypotheses required to complete the modeling can differ between these approaches, they all rely on the definition of a scalar space coordinate system centered on the thin diffusive-reactive layers.

Along these lines, strategies were developed to solve laminar and canonical combustion problems directly in scalar space. The most commonly used is the mixture fraction $(Z=0$ in the oxidizer stream, $Z=1$ in the fuel feeding stream), which is a passive scalar that can be related to the local equivalence ratio of the mixture in non-premixed systems and that can be defined in multicomponent flows from a set of representative species mass fractions [14, 15]. The solving of one-dimensional counter-flowing diffusion flames was for instance intensively studied in mixture fraction space, including various levels of complexity [16 19]. Sometimes scalars are combined with other coordinates. In the context of reacting mixing layers in stagnation-type flows subject to both time-varying strain and pressure, a thermal-conductivity-weighted transverse coordinate was found to be very effective [20].

The normalized progress variable ( $c=0$ in the fresh gases, $c=1$ in the fully burnt products) is widely used for premixed flames and the solving of freely propagating laminar premixed flames in progress variable space was reported [21, 22]. Finally, the combination of both mixture fraction and progress variable allows for addressing partially premixed and non-premixed flames in a 
two-dimensional scalar space [23, 24].

Up to very recently, the scalar space formalism was not self-consistent. Indeed, the jacobian for transformation between the physical and scalar coordinates contains the physical-space gradient of the scalar coordinates, which was left as a free parameter in the balance equations. To overcome this strong limitation, in [22] the balance equation for the gradient is also projected in scalar space, to come up with a fully self-consistent scalar space solution for freely propagating unstrained onedimensional premixed flames. It is proposed in this work to extend and generalise this self-consistent solution procedure.

First, premixed flamelet equations for temperature, species mass fractions and progress variable gradient are derived incorporating effects of strain and curvature, with only flow quantities as flamelet parameters. The equation set is expressed with respect to the progress variable, which spans the scalar space. Subsequently, numerical methods for solving the flamelet equations are briefly revisited. It is shown that the asymptotic limit of the zero-dimensional and constant pressure ignition problem is well recovered by the proposed formulation. Then, three canonical configurations, namely the stagnation flame, the tubular flame and the spherical expanding flame, are simulated in progress variable space with detailed chemistry and complex transport properties. Three fuels are studied: hydrogen, methane and ethanol. By comparison to physical space reference solutions and experimental measurements of the literature, it is demonstrated that effects of unsteadiness, strain and curvature are well captured by the novel set of premixed flamelet equations, including negative stretch, opening new perspectives for turbulent combustion modeling.

\section{Flame and flow parameters}

\subsection{Budget equations}

The instationary balance equations for temperature $T$ and the species mass fractions $Y_{i}$ serve as a starting point for the flamelet model derivation. They can be expressed with respect to the 3D physical space as

$$
\begin{aligned}
\rho c_{p} \frac{\partial T}{\partial t}+\rho c_{p} \mathbf{u} \cdot \nabla T & =\nabla \cdot(\lambda \nabla T)-\rho \sum_{k}^{n_{s}} c_{p, k} Y_{k} \mathbf{V}_{k} \cdot \nabla T+\dot{\omega}_{T}, \\
\rho \frac{\partial Y_{i}}{\partial t}+\rho \mathbf{u} \cdot \nabla Y_{i} & =-\nabla \cdot\left(\rho Y_{i} \mathbf{V}_{i}\right)+\dot{\omega}_{i}
\end{aligned}
$$


where $\rho$ is the density, $c_{p}$ the specific heat capacity, $\lambda$ the thermal conductivity, $\mathbf{u}$ the velocity vector and $\mathbf{V}_{k}$ the diffusion velocity vector of species $k$. The quantities $\dot{\omega}_{T}$ and $\dot{\omega}_{i}$ denote the source terms due to gas phase chemistry for temperature and species, respectively.

The progress variable is defined as a combination of species according to $Y_{c}=\sum_{i}^{n_{s}} \alpha_{i} Y_{i}$, where $\alpha_{i}$ is a species specific weighting factor and $n_{s}$ is the total number of species. The analogous summation over Eq. (2) yields a balance equation for the progress variable:

$$
\rho \frac{\partial Y_{c}}{\partial t}+\rho \mathbf{u} \cdot \nabla Y_{c}=-\nabla \cdot\left(\rho Y_{c} \mathbf{V}_{c}\right)+\dot{\omega}_{c}
$$

where the diffusive flux of the progress variable is defined as $Y_{c} \mathbf{V}_{c}=\sum_{i}^{n_{s}} \alpha_{i} Y_{i} \mathbf{V}_{i}$ and the source term as $\dot{\omega}_{c}=\sum_{i}^{n_{s}} \alpha_{i} \dot{\omega}_{i}$. A fundamental requirement for the choice of the progress variable is that it varies strictly monotonically throughout the flame front. Note that its definition depends on the fuel-oxidizer system and is not always trivial to identify [25 27].

\subsection{Flame speed and displacement speed}

The flame is assumed to be a thin sheet of finite thickness, which is not necessarily flat, and which can be represented by a collection of $Y_{c}$-isosurfaces (analogy to FGM [28]). The motion of each surface is described by the kinematic condition [28, 29]

$$
\frac{\mathrm{d} Y_{c}}{\mathrm{~d} t}=\frac{\partial Y_{c}}{\partial t}+\mathbf{s}_{f} \cdot \nabla Y_{c}=0
$$

which states that a point on the isosurface of $Y_{c}$ remains on this surface for all $t$. For a fixed observer the flame moves with the apparent flame speed $\mathbf{s}_{f}$ in the physical space, which is composed of the flow velocity vector $\mathbf{u}$ and the flame displacement speed $s_{d}$ directed opposite to the normalized gradient $\mathbf{n}_{c}=\nabla Y_{c} /\left|\nabla Y_{c}\right|$

$$
\mathbf{s}_{f}=\mathbf{u}-s_{d} \mathbf{n}_{c}
$$

Introducing Eq. (5) in Eq. (4) one obtains

$$
\rho \frac{\partial Y_{c}}{\partial t}+\rho \mathbf{u} \cdot \nabla Y_{c}=\rho s_{d}\left|\nabla Y_{c}\right|
$$


which further yields an expression for the local mass burning rate $\rho s_{d}$ of a premixed flame sheet, when further employing Eq. (3) to replace the left hand side in the above equation

$$
\rho s_{d}=\frac{1}{\left|\nabla Y_{c}\right|}\left(-\nabla \cdot\left(\rho Y_{c} \mathbf{V}_{c}\right)+\dot{\omega}_{c}\right) .
$$

\subsection{Flame stretch, strain and curvature}

Flame stretch is a key quantity influencing a flame's structure, extinction behavior, and its mass burning rate. Here, important characteristics of the flame stretch concept are briefly revisited before incorporating stretch effects into the flamelet model.

A first generic definition of flame stretch was given by Williams [30]

$$
K_{A}=\frac{1}{A} \frac{\mathrm{d} A}{\mathrm{~d} t}
$$

which describes the fractional area change of a small flame surface element moving with an infinitely thin flame sheet. In this context, extensive theory has been developed and many practical flame configurations have been studied and discussed [29, 31 33]. The formulation for flame stretch was later on extended by de Goey and ten Thije Boonkkamp [34] considering the mass $M(t)$ in an infinitesimal volume $V(t)$ moving in the flame of finite thickness

$$
K=\frac{1}{M} \frac{\mathrm{d} M}{\mathrm{~d} t} \quad \text { with } \quad M(t)=\int_{V(t)} \rho \mathrm{d} V .
$$

While the formulation by Williams [30] is also referred to as weak stretch, the latter is referred to as strong stretch further accounting for the resolved diffusive layer in the vicinity of the flame [28]. The stretch rate $K$ can be defined as [34]

$$
\rho K=\frac{\partial \rho}{\partial t}+\nabla \cdot\left(\rho \mathbf{s}_{f}\right)
$$

and can be rewritten using Eq. (5) according to [34]

$$
\rho K=-\nabla \cdot\left(\rho s_{d} \mathbf{n}_{c}\right)
$$

which illustrates that the stretch rate is related to variations of the normal mass flux through 
the flame surface [34]. Expanding Eq. (10), the single contributions to flame stretch can be examined [34]

$$
K=\nabla \cdot \mathbf{s}_{f}+\frac{1}{\rho}\left(\frac{\partial \rho}{\partial t}+\mathbf{s}_{f} \cdot \nabla \rho\right)=\nabla \cdot \mathbf{u}_{t}-s_{f} \kappa_{c}+\mathbf{n}_{c} \cdot \nabla s_{f}+\frac{1}{\rho} \frac{\partial \rho}{\partial t}
$$

where the curvature of the $Y_{c}$-isosurface is defined as

$$
\kappa_{c}=-\nabla \cdot \mathbf{n}_{c}
$$

the flame-tangential (flow) velocity vector is defined as $\mathbf{u}_{t}=\mathbf{u}-\left(\mathbf{n}_{c} \cdot \mathbf{u}\right) \mathbf{n}_{c}$ and $s_{f}=\mathbf{s}_{f} \cdot \mathbf{n}_{c}$ is the projected flame speed in flame-normal direction. The first and the second term on the right side of Eq. (12) can also be found from weak stretch theory 31 33] and can be interpreted as flame-tangential strain and flame stretch through instationary movement of a curved flame sheet. The third term in Eq. (12) arises from instationary flame-normal stretch, such that the flame-normal velocity $s_{f}$ varies between different $Y_{c}$-isosurfaces. The fourth term in Eq. (12) originates from density variations along flame isosurfaces. Due to the fact that isosurfaces of $\rho$ are assumed to align with $Y_{c}$-isosurfaces, the last two terms in Eq. (12) cancel, which is readily seen from the kinematic condition Eq. (4).

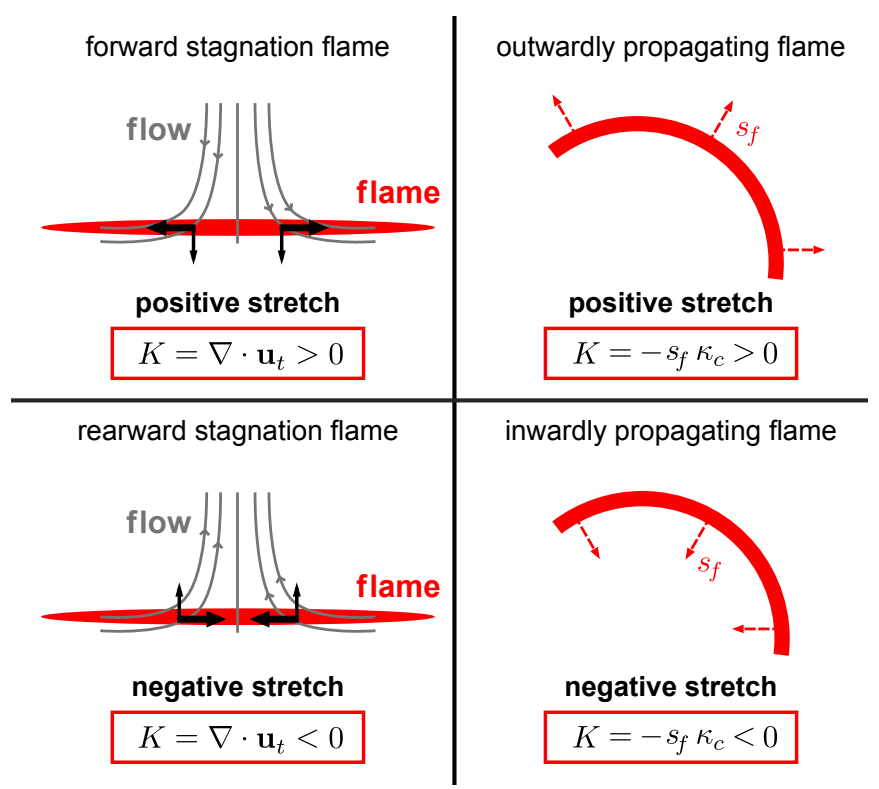

Figure 1: Schematic flame configurations which experience stretch due to strain (left column) or stretch due to curvature (right column) 35. 
The relevant effects described by the first two terms in Eq. 12 are shown in Fig. 1 for flames which exhibit either stretch due to flame-tangential strain (left column) or stretch due to movement of a curved flame sheet (right column). For the latter, the flame moves in the flame-normal direction such that the flame surface increases (positive stretch, outward flame propagation) or decreases (negative stretch, inward flame propagation). Hence, stretch conditions can be readily associated with the surface-based stretch definition, see Eq. (8). For the flames in a forward or rearward stagnation flow, flame-tangential straining can be understood by considering the flow velocity components projected into the flame-tangential plane (thick arrows). Of the flames depicted in Fig. 1] only the positively stretched flames can be studied under controlled conditions in a laboratory. The rearward stagnation flame is inherently unstable and the inwardly propagating flame cannot reproducibly be ignited in perfect spherical (or cylindrical) shape before it starts to propagate. Overall, it is hardly possible to establish significant negative strain conditions with laboratory flames? ${ }^{1}$, however, large negative strain rates can be identified in turbulent flames [37, 38]. It will be shown further below that the composition space flame model developed here allows to study also negative strain conditions, which is, with few exceptions [39, 40], not possible with conventional physical space flame solvers.

\section{Progress variable space formulation}

\subsection{Transformation rules}

The governing equations are transformed from physical space $(t, \mathbf{x})$ to the progress variable space $\left(\tau, Y_{c}(t, \mathbf{x})\right)$, where $\tau$ represents a flamelet time defined by $\tau=t$. The corresponding temporal transformation rule reads for the exemplary scalar quantity $\phi$

$$
\frac{\partial \phi}{\partial t}=\frac{\partial \phi}{\partial \tau}+\frac{\partial Y_{c}}{\partial t} \frac{\partial \phi}{\partial Y_{c}}
$$

\footnotetext{
${ }^{1}$ The Bunsen flame, which exhibits negative stretch, is one of the few exceptions. However, it has been realized recently that the structure of a Bunsen flame is controlled by rather complicated physics [36]. Its stretch conditions are non-uniform and have to be considered at least two-dimensional.
} 
For any quantity $\phi=\phi\left(Y_{c}\right)$, the following spatial transformation rules are verified:

$$
\begin{aligned}
\nabla \phi & =\nabla Y_{c} \frac{\partial \phi}{\partial Y_{c}} \\
\nabla^{2} \phi & =\left|\nabla Y_{c}\right|^{2} \frac{\partial^{2} \phi}{\partial Y_{c}^{2}}+\nabla^{2} Y_{c} \frac{\partial \phi}{\partial Y_{c}} .
\end{aligned}
$$

The second order derivative $\nabla^{2} Y_{c}$ is decomposed into its normal and curvature contribution [41]

$$
\nabla^{2} Y_{c}=\mathbf{n n}: \nabla\left(\nabla Y_{c}\right)+\left|\nabla Y_{c}\right| \nabla \cdot \mathbf{n}
$$

One can write $\nabla\left(\left|\nabla Y_{c}\right|\right)=\mathbf{n} \cdot \nabla\left(\nabla Y_{c}\right)$, then $\mathbf{n n}: \nabla\left(\nabla Y_{c}\right)=\mathbf{n} \cdot \nabla\left(\left|\nabla Y_{c}\right|\right)=\left|\nabla Y_{c}\right|\left(\partial\left|\nabla Y_{c}\right| / \partial Y_{c}\right)$, where Eq. (15) is also applied to $\nabla\left(\left|\nabla Y_{c}\right|\right)$. Combined with Eqs. (16) and (17), this leads to

$$
\nabla^{2} \phi=\left|\nabla Y_{c}\right|^{2} \frac{\partial^{2} \phi}{\partial Y_{c}^{2}}+\left|\nabla Y_{c}\right|\left(\frac{\partial\left|\nabla Y_{c}\right|}{\partial Y_{c}}+\nabla \cdot \mathbf{n}\right) \frac{\partial \phi}{\partial Y_{c}} .
$$

In Eq. 18, the progress variable gradient $g_{c}=\left|\nabla Y_{c}\right|$ is introduced. This quantity plays a central role in the flamelet transformation since it relates $Y_{c}$-space to the physical space. Traditionally, $g_{c}$ is used to define the scalar dissipation rate

$$
\chi_{c}=2 D_{c} \nabla Y_{c} \cdot \nabla Y_{c}=2 D_{c} g_{c}^{2} .
$$

While the gradient (or scalar dissipation rate) can be modeled for non-premixed flamelets [42], it has to be treated as a dependent quantity for premixed flamelets [22].

\subsection{Diffusion modeling in progress variable space}

Keeping in mind that the species diffusion velocity $\mathbf{V}_{i}$ contains gradient information, it is transformed using the spatial transformation rule Eq. (15) [22, 43]

$$
\rho Y_{i} \mathbf{V}_{i}=\rho Y_{i} \tilde{V}_{i} \nabla Y_{c}
$$

where $\tilde{V}_{i}$ represents a diffusion velocity in progress variable space. Instead of gradients with respect to physical space coordinates, $\tilde{V}_{i}$ analogously contains gradients with respect to the conditioning variable $Y_{c}$ and can therefore be computed from conventional transport libraries on a $Y_{c^{-}}$-grid 
(e.g. cantera 44] or EGlib [45, 46]). Consequently, the approach allows arbitrary diffusion models to be incorporated in progress variable space without notational overhead. In this work, a mixture averaged diffusion model [47] with a correction velocity for mass conservation [48] is applied. Additionally, thermal diffusion [45, 46] is considered for $\mathrm{H}_{2}$-air flames.

\subsection{Composition space equations}

Composition space (or flamelet) equations are obtained by applying the transformation rules in Sec. 3.1 to Eqs. (1) and (2). Furthermore, noticing that $g_{c}=\left|\nabla Y_{c}\right|=\mathbf{n} \cdot \nabla Y_{c}$, an equation for the progress variable gradient $g_{c}$ is obtained by differentiating (and transforming) the balance equation for $Y_{c}$ according to

$$
\mathbf{n} \cdot \nabla\left[\rho \frac{\partial Y_{c}}{\partial t}+\rho \mathbf{u} \cdot \nabla Y_{c}=-\nabla \cdot\left(\rho Y_{c} \mathbf{V}_{c}\right)+\dot{\omega}_{c}\right]
$$

Details of the derivation are available in the supplementary material. The premixed flamelet equations for species, temperature and progress variable gradient are obtained as

$$
\begin{aligned}
\rho \frac{\partial Y_{i}}{\partial \tau} & =-g_{c} \frac{\partial}{\partial Y_{c}}\left(g_{c} \rho Y_{i} \tilde{V}_{i}\right)+g_{c} \frac{\partial}{\partial Y_{c}}\left(g_{c} \rho Y_{c} \tilde{V}_{c}\right) \frac{\partial Y_{i}}{\partial Y_{c}} \\
& +\rho g_{c} \kappa_{c}\left(Y_{i} \tilde{V}_{i}-Y_{c} \tilde{V}_{c} \frac{\partial Y_{i}}{\partial Y_{c}}\right)-\dot{\omega}_{c} \frac{\partial Y_{i}}{\partial Y_{c}}+\dot{\omega}_{i} \\
\rho \frac{\partial T}{\partial \tau} & =\frac{g_{c}}{c_{p}} \frac{\partial}{\partial Y_{c}}\left(g_{c} \lambda \frac{\partial T}{\partial Y_{c}}\right)+g_{c} \frac{\partial}{\partial Y_{c}}\left(g_{c} \rho Y_{c} \tilde{V}_{c}\right) \frac{\partial T}{\partial Y_{c}}-\rho g_{c}^{2} \sum_{k}^{n_{s}} \frac{c_{p, k}}{c_{p}} Y_{k} \tilde{V}_{k} \frac{\partial T}{\partial Y_{c}} \\
& -\rho g_{c} \kappa_{c}\left(\frac{\lambda}{\rho c_{p}}+Y_{c} \tilde{V}_{c}\right) \frac{\partial T}{\partial Y_{c}}-\dot{\omega}_{c} \frac{\partial T}{\partial Y_{c}}+\frac{\dot{\omega}_{T}}{c_{p}}, \\
0 & =-g_{c}^{2} \frac{\partial^{2}}{\partial Y_{c}^{2}}\left(g_{c} \rho Y_{c} \tilde{V}_{c}\right)+g_{c}^{2} \frac{\partial}{\partial Y_{c}}\left(\kappa_{c} \rho Y_{c} \tilde{V}_{c}\right)-\dot{\omega}_{c} \frac{\partial g_{c}}{\partial Y_{c}}+g_{c} \frac{\partial \dot{\omega}_{c}}{\partial Y_{c}}+\rho K_{s} g_{c} .
\end{aligned}
$$

These premixed flame equations are similar to the ones presented in our earlier work [22], with additional terms to incorporate the flamelet parameters strain $K_{s}$ and curvature $\kappa_{c}$. The quantity $K_{s}$ differs from the overall stretch rate $K$ and represents straining imposed on the flame by the flow field

$$
K_{s}=-\frac{1}{\rho} \frac{\partial\left(\rho s_{d}\right)}{\partial n}=K-s_{d} \kappa_{c} \stackrel{12}{=} \nabla \cdot \mathbf{u}_{t}-\left(s_{f}+s_{d}\right) \kappa_{c}=\nabla \cdot \mathbf{u}_{t}-u_{g} \kappa_{c}
$$

where $u_{g}=\mathbf{n}_{c} \cdot \mathbf{u}$ is the flow velocity along the flame-normal direction. Formally, the flame stretch $K$ can be split into flow straining $K_{s}$, and flame stretch due to the self-propagation of the (curved) 
flame sheet described by $K_{c}=-s_{d} \kappa_{c}$. This splitting procedure has been carried out by other authors before [39, 49]. The relation (25) indicates that $K_{s}$ solely depends on flow quantities. This is particularly important, since the flame displacement speed $s_{d}$ is a flame response obtained by solving the premixed flamelet equations and shall therefore not appear in the definition of the strain rate, which is one of the flame control parameters.

Note that species and temperature equation are instationary in composition space, while the gradient equation is not. When prescribing a certain set of flamelet parameters the flame topology becomes implicitly fixed. Due to the fact that the gradient represents the spatial mapping from composition space to physical space it also has to be fixed for a given combination of $K_{s}$ and $\kappa_{c}$. A similar finding was reported for FGM by van Oijen et al. [28] who showed that the equation for the progress variable in the flame-adapted coordinate system is stationary.

\subsection{Boundary conditions}

The conditioning variable $Y_{c}$ varies on the interval $\left[Y_{c, \min } Y_{c, \max }\right]$ and the exact values of minimum and maximum depend on the progress variable definition. At the left boundary $\left(Y_{c, \min }\right)$ Dirichlet boundary conditions are imposed

$$
Y_{c}=Y_{c, \min }: \quad Y_{i}=Y_{i, 0}, T=T_{0}, g_{c}=0
$$

which are determined a-priori from the unreacted mixture of fresh gases.

For zero strain and curvature, an unstrained, planar freely-propagating flame and the constant pressure homogeneous ignition can be described by the flamelet equations (22), (23) and 24] 22]. In this case, the conditions at the right boundary $\left(Y_{c, \max }\right)$ correspond to the chemical equilibrium which can be determined from the fresh gas mixture. Hence, it can also be described by Dirichlet boundary conditions

$$
Y_{c}=Y_{c, \text { max }}=Y_{c, \text { eq }}: \quad Y_{i}=Y_{i, \mathrm{eq}}, T=T_{\mathrm{eq}}, g_{c}=0
$$

where the subscript "eq" refers to chemical equilibrium conditions.

However, for non-zero strain or curvature, the right boundary location $Y_{c, \text { max }}$ becomes an eigenvalue of the problem since premixed flames can exhibit sub- or super-equilibrium conditions 
(also called hot spots [50 52]). This implies that the $Y_{c^{-}}$-space can contract or expand and that the right boundary has to be implemented as a moving boundary. For the numerical solution, the flamelet equations, Eqs. (22)-(24), are therefore transformed to a normalized progress variable space (c-space). The procedure is described in the supplementary material.

\subsection{Closure of the flamelet equations}

With the flamelet gradient equation, Eq. 24, the linkage of the flamelet model to the flow is no longer inherently captured by prescribing the gradient or scalar dissipation rate as for previous premixed flamelet formulations in progress variable space [21, 23, 53]. Instead, the effects of the flow on the flamelet structure are represented directly by strain and curvature, which appear explicitly in the equations and which have been proven to be fundamental flame parameters [54]. A closure for these flame parameters is obtained by approximating $K_{s}$ and $\kappa_{c}$ by representative constant values. The approach yields an accurate and self-contained premixed flamelet model, including flamelets subject to strain and curvature. This is demonstrated in Sec. 5 by comparing flamelet solutions to well-established numerical models (formulated in the physical space) and experiments for stagnation flames, tubular flames and spherical expanding flames.

\section{Numerical methods}

The stationary solution of the flamelet equations is obtained with a hybrid damped Newton method [55] with an in-house $\mathrm{C}++$ flame solver [56]. A straight line is prescribed as the initial solution which connects the fresh gas mixture (left boundary condition) with the corresponding equilibrium conditions (right boundary initialization). In a pseudo-transient time-stepping procedure, the initial solution is first relaxed for few time steps before a stationary solution by Newton iteration is attempted. If the stationary solver fails, the solution is advanced for a fixed number of additional time steps and the stationary solver is rerun. This procedure is repeated until convergence of the stationary solver. Starting from a coarse grid with 8-30 points, the grid is adaptively refined after each convergent solution until a user-specified target. For the evaluation of diffusion coefficients and chemical source terms, the EGlib [45, 46] and an in-house chemistry library are used, respectively. The chemical reaction mechanism by Varga et al. [57] (12 species, 29 reactions) is applied for $\mathrm{H}_{2}$-air flames, the GRI 3.0 mechanism by Smith et al. [58] (53 species, 325 reactions) for $\mathrm{CH}_{4}$-air flames, and the mechanism by Olm et al. [59] (47 species, 250 reactions) for $\mathrm{C}_{2} \mathrm{H}_{5} \mathrm{OH}$-air flames. 


\section{Self-contained scalar space flame simulations}

A homogeneous reactor (ignition problem) and 1D canonical laminar flames are studied applying the previously introduced formalism. By comparison to corresponding physical space solutions the progress variable space model is validated and the numerical solutions are complemented by suitable experimental results. Table 1 contains an overview of the configurations studied. For the flame configurations, $\mathrm{H}_{2}$-air and $\mathrm{CH}_{4}$-air flames are considered due to the availability of extensive reference data from the literature. Fuel-lean flames are investigated in which the fuel Lewis number $\left(\mathrm{Le}_{\mathrm{H}_{2}} \approx 0.3, \mathrm{Le}_{\mathrm{CH}_{4}} \approx 1\right)$ determines how strain and curvature affect flame structures, it is therefore denoted as the effective Lewis number Le [54]. In order to study flame responses for Le $>1$, additionally $\mathrm{C}_{2} \mathrm{H}_{5} \mathrm{OH}$-air flames are considered $\left(\mathrm{Le}_{\mathrm{C}_{2} \mathrm{H}_{5} \mathrm{OH}} \approx 1.6\right)$.

The progress variable definitions for the flamelet calculations are chosen as $Y_{c}=Y_{\mathrm{H}_{2} \mathrm{O}}-Y_{\mathrm{H}_{2}}-Y_{\mathrm{O}_{2}}$ ( $\mathrm{H}_{2}$-air flames) and $Y_{c}=Y_{\mathrm{CO}_{2}}+Y_{\mathrm{H}_{2} \mathrm{O}}+10 Y_{\mathrm{H}_{2}}-Y_{\mathrm{O}_{2}}\left(\mathrm{CH}_{4}\right.$ - and $\mathrm{C}_{2} \mathrm{H}_{5} \mathrm{OH}$-flames). Also other progress variable definitions would yield accurate flamelet results, often a combination of product (positive weight in definition) and educt species (negative weight) is suitable. For the hydrocarbon flames the weight for the mass fraction of $\mathrm{H}_{2}$ was increased due to its low molecular mass. Note that it is important to include $\mathrm{H}_{2}$ in the definition of the progress variable to correctly capture differential diffusion effects in the preheat zone of a premixed flame with a premixed flamelet model [22].

Table 1: Characteristics of several canonical combustion configurations (0D and 1D) with respect to unsteady effects and the flamelet parameters strain $K_{s}$ and curvature $\kappa_{c}$.

\begin{tabular}{llcccc}
\hline case & acronym & strain & curvature & unsteadiness & reference \\
\hline homogeneous reactor & HR & - & - & + & this work \\
\hline freely-propagating flame & FP & - & - & - & {$[22]$} \\
stagnation flame & STAG & + & - & - & this work \\
tubular stagnation flame & TUB & + & + & - & this work \\
spherical expanding flame & SEF & + & + & + & this work \\
\hline
\end{tabular}

\subsection{Constant pressure homogeneous ignition}

The transient evolution of temperature and species mass fractions in the constant pressure homogeneous reactor (HR) are described neglecting convective and diffusive transport terms in 
Eqs. (1) and (2), which yields the following equation set:

$$
\rho \frac{\partial T}{\partial t}=\frac{\dot{\omega}_{T}}{c_{p}} \quad \text { and } \quad \rho \frac{\partial Y_{i}}{\partial t}=\dot{\omega}_{i}
$$

With the transient evolution of $Y_{i}$ also the reaction progress variable changes. The summation over the species equation according to the definition of the progress variable yields

$$
\rho \frac{\partial Y_{c}}{\partial t}=\dot{\omega}_{c}
$$

Defining the progress variable such that it includes species which vary during all phases of the ignition process (thus, preferably major species) allows the mapping of the thermochemical variables (here $T$ ) to the reaction progress variable in time

$$
\frac{\partial T}{\partial t}=\frac{\partial Y_{c}}{\partial t} \frac{\partial T}{\partial Y_{c}}
$$

which defines a temporal transformation rule different from Eq. (14), since it does not consider the flamelet time $\tau$. With this, the constant pressure homogeneous ignition is described in progress variable space by combining Eqs. (28)- 30

$$
\frac{\partial T}{\partial Y_{c}}=\frac{1}{c_{p}} \frac{\dot{\omega}_{T}}{\dot{\omega}_{c}} \text { and } \quad \frac{\partial Y_{i}}{\partial Y_{c}}=\frac{\dot{\omega}_{i}}{\dot{\omega}_{c}}
$$

This equation set has previously been used to describe autoignition [60] and contains formally no transient term. The Eqs. (31) are one-dimensional and imply that a trajectory in composition space can be directly constructed by integrating along $Y_{c}$ (assuming a monotonically varying progress variable). This model shall be denoted as the progress variable space reactor (PVR).

Figure 2 displays the constant pressure ignition of a stoichiometric $\mathrm{CH}_{4}$-air mixture at $1500 \mathrm{~K}$. The left graph of this figure shows the evolution of the temperature and the mass fractions for $\mathrm{CO}_{2}$ and the radical $\mathrm{OH}$ versus time $t$ (i.e. simulated solving Eq. (28)). The middle graph shows a projection of the temperature profile into progress variable space, where $Y_{c}=Y_{\mathrm{CO}_{2}}$. It is observed that the PVR model (Eq. (31) accurately reproduces this progress variable space trajectory. Furthermore, the time integration (in flamelet time $\tau$ ) of the premixed flamelet model (PFLT) is 


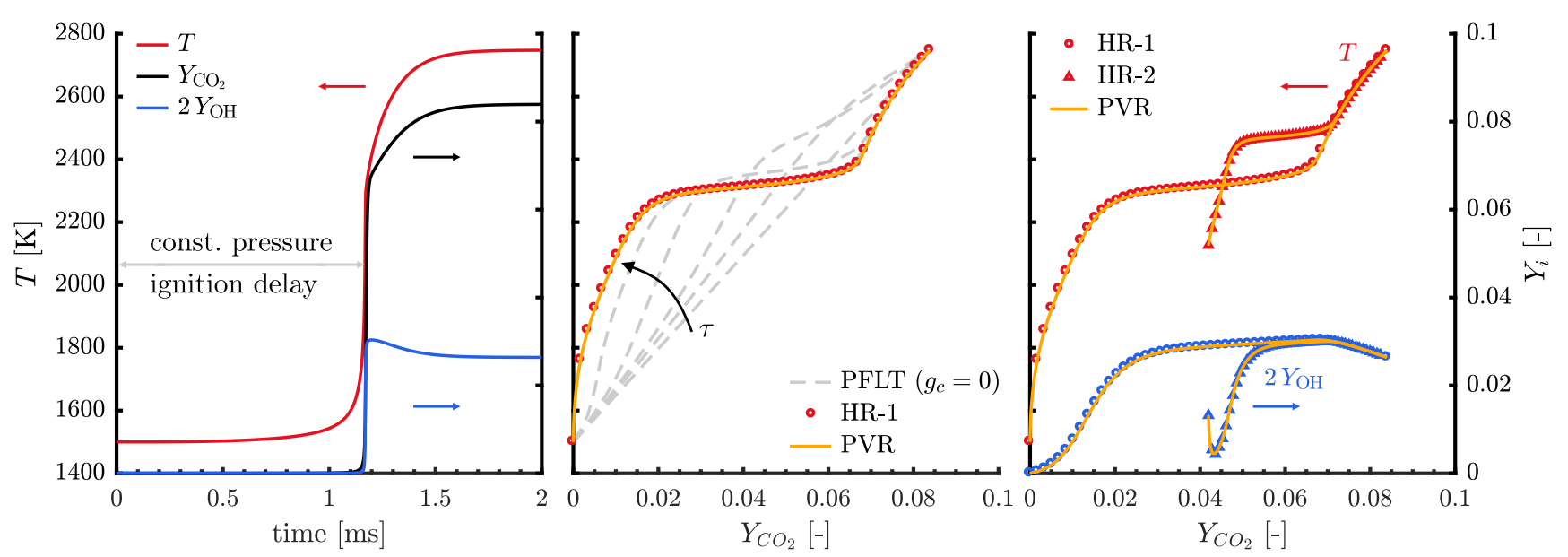

Figure 2: Left: Constant pressure ignition of a homogeneous stoichiometric $\mathrm{CH}_{4}$-air mixture at $1500 \mathrm{~K}$ versus time (case HR-1). Middle: The temperature profile for the case HR-1 mapped into progress variable space $\left(Y_{c}=Y_{\mathrm{CO}_{2}}\right)$. The temperature profile is computed with three different models: homogeneous reactor (HR), reactor in progress variable space $(\mathrm{PVR})$ and the transient premixed flamelet model (PFLT, $\left.g_{c}=0\right)$. Right: Progress variable space trajectories of two different constant pressure ignition cases recomputed with the models HR and PVR. The initial state of case HR-2 consists of a $50 \%$ fresh stoichiometric $\mathrm{CH}_{4}$-air mixture at $1500 \mathrm{~K}$ and $50 \%$ hot products with the same enthalpy level.

shown, which is first initialized with a linear profile between fresh gases and chemical equilibrium. Due to homogeneity of the mixture, the progress variable gradient $g_{c}=\left|\nabla Y_{c}\right|$ equals to zero and the premixed flamelet equations $(23)$ and $(22)$ reduce to

$$
\begin{aligned}
\rho \frac{\partial T}{\partial \tau} & =-\dot{\omega}_{c} \frac{\partial T}{\partial Y_{c}}+\frac{\dot{\omega}_{T}}{c_{p}}, \\
\rho \frac{\partial Y_{i}}{\partial \tau} & =-\dot{\omega}_{c} \frac{\partial Y_{i}}{\partial Y_{c}}+\dot{\omega}_{i} .
\end{aligned}
$$

It is readily shown, that the stationary solution of this equation set is equal to Eqs. (31) and as seen from the mid graph in Fig. 2 the solution for the PFLT model relaxes to the solutions for the models HR and PVR for increasing $\tau$.

These results illustrate that the behavior of the transient ignition are captured well by the stationary solution of the premixed flamelet model in progress variable space. While there are two terms in the temporal transformation rule, Eq. (14), which formally describe transient effects, $\partial T / \partial \tau$ and $\partial Y_{c} / \partial t$, the former can hardly be interpreted from a physical point of view. This is due to the fact that transient variations of thermodynamical quantities (i.e. species and temperature) with $\tau$ would require that the progress variable remains fixed. However, this is rarely the case for most thermochemical variables, since the conditioning variable $Y_{c}$ is defined as a combination 
of species and therefore dynamically linked to the full thermodynamical state through chemical reactions and thermodynamics. Also for fast reactions of radical species, the stationary solution of the premixed flamelet model is appropriate, as shown by the right graph in Fig. 2. Considering a highly reactive mixture (case HR-2), which is obtained by mixing $50 \%$ of fresh gases and $50 \%$ of hot products by mass, the PVR model (equivalently the stationary PFLT model) still accurately captures the evolution of temperature and the radical $\mathrm{OH}$ in progress variable space. This also applies to other radical species (not shown).

\subsection{Canonical laminar premixed flames}

For premixed combustion, the unstretched laminar burning velocity $s_{u}^{0}$ represents an important characteristic quantity which inherently contains fundamental information regarding the reactivity, diffusivity and exothermicity of a combustible mixture [61] (the superscript 0 marks the stretchless reference condition). While the reference quantity $s_{u}^{0}$ solely depends on the thermochemical state of the fresh gas mixture, the burning velocity $s_{u}$ of a premixed flame can be influenced by multiple factors such as strain, curvature or heat-loss. It is defined at the edge of unburned gases and is thereby distinguished from the flame displacement speed $s_{d}$, which varies throughout the flame zone due to thermal expansion. The latter can be computed from a composition space flamelet solution using the transformed Eq. (7):

$$
s_{d}=\frac{1}{\rho}\left[-\frac{\partial}{\partial Y_{c}}\left(g_{c} \rho Y_{c} \tilde{V}_{c}\right)+\frac{\dot{\omega}_{c}}{g_{c}}\right] \text {. }
$$

The laminar burning velocity $s_{u}$ is then determined with the above expression at the unburned edge of the flame, which is defined by an isotherm $T=T_{u}+5 \mathrm{~K}$ [49] (with $T_{u}$ being the temperature of the unburnt gases). Furthermore, the absolute flame speed $s_{f}$ can be defined, which marks the apparent speed of the flame for a fixed observer

$$
s_{f}=u_{g}-s_{u}
$$

where $u_{g}$ is the flame-normal velocity component of the flow at the unburned edge of the flame. Note that the negative sign for $s_{u}$ originates from its direction opposite to the normalized gradient $\mathbf{n}_{c}=$ $\nabla Y_{c} /\left|\nabla Y_{c}\right|$. For the ideal freely-propagating reference flame, $s_{f}$ is constant throughout the flame 
zone. However, as soon as the flame becomes stretched (due to strain and/or curvature), flame speeds are more difficult to evaluate, both experimentally and numerically [62].

Three stretched flame configurations with successively more complex conditions (see Tab. 1) are discussed in this section: the stagnation flame (STAG), the tubular stagnation flame (TUB) and the spherical expanding flame (SEF).

\subsubsection{Planar stagnation flames}

Planar stagnation flames have been used to study flame structures, propagation and extinction, both theoretically and experimentally, and a broad overview can be found in the review paper by Egolfopoulos et al. [36]. Among other possibilities, these types of flames can be established by directing a stream of combustible fresh gases towards a wall (single jet-wall configuration, c.f. Fig. 3), or by two counterflowing jets of the same chemical composition (symmetric twin flame configuration). The most prominent characteristic of this flame configuration is that (in the absence of wall heat losses) the only external flow effect on the flame is flame-tangential strain, which can be studied and quantified systematically [36].

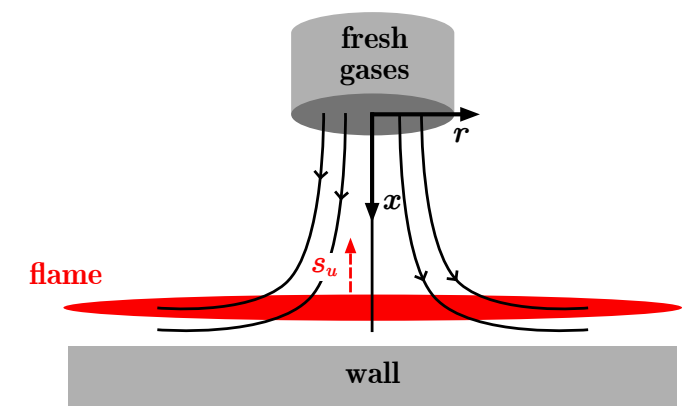

Figure 3: Schematic of a planar stagnation flame.

Physical space model. For planar flames established in a stagnation flow it has been shown that thermochemical quantities are a function of the axial coordinate $x$ only [63]. Thus, a one-dimensional equation set can be derived from a similarity transformation which describes the flame structure along the flame centerline. Using the model by Kee et al. [63] a stagnation flame is solved imposing inflow boundary conditions from the nozzle and an adiabatic wall on the other side, with zero gradient boundary conditions for thermochemical quantities. For the flow, the wall is modeled as a slip wall, where the axial velocity becomes zero, but the radial velocity gradient is allowed 
to assume finite values. The numerical model therefore corresponds to a symmetrical twin flame configuration [64].

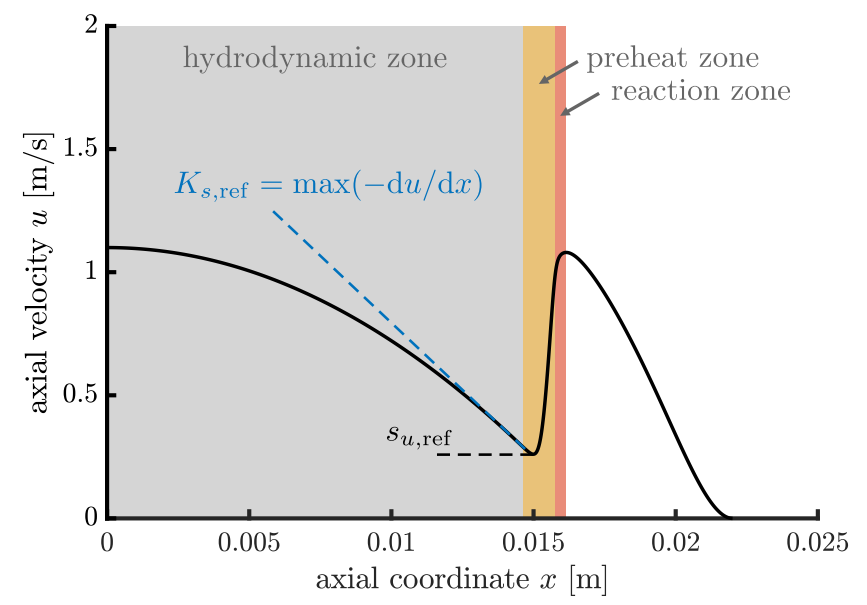

Figure 4: Flow field of the stagnation flame with the reference flame speed $s_{u \text {,ref }}$ and the reference strain rate $K_{s, \text { ref }}$, evaluated from the steepest velocity gradient upstream of the flame. Recreated according to Ref. [36].

Flow profile and strain rate. To facilitate a reasonable comparison of the numerical results with experiments, the flow field and strain profile of stagnation flames are examined. Figure 4 shows the flow field solution of the stagnation flame which can be divided into three characteristic zones: (1) the hydrodynamic zone, (2) the premixed flame's preheat zone, where the flow velocity increases due to thermal expansion, and (3) the premixed flame's reaction zone [36]. For this characteristic flow profile two quantities can be identified which are readily accessible with experimental methods: the minimum axial velocity upstream of the flame $s_{u, \text { ref }}$ (note that $s_{u}^{0} \neq s_{u, \text { ref }}$ ) and the steepest gradient of the velocity profile upstream of the flame $K_{s, \text { ref }}$. The quantity $s_{u \text {,ref }}$ can be recorded as a function of $K_{s \text {,ref }}$ experimentally and this method is commonly used to determine $s_{u}^{0}$ by extrapolation to zero stretch [36, 65, 66].

Modeling strain in progress variable space. For the premixed flamelet model the strain rate is defined according to Eq. 25), which is shown for an exemplary flame configuration in Fig. 5 in physical space (coordinate $x$, left) and in normalized progress variable space (coordinate $c$, middle). Note that the strain rate $K_{s, \text { ref }}$ is proportional to the gradient of the velocity $u$ (c.f. Fig. 4), whereas $K_{s}$, the flamelet parameter, is proportional to the gradient of the mass flux $\rho u$. Nonetheless, both quantities agree well at the unburned edge of the flame $(c=0)$ since the effect of thermal expansion (thus, the density gradient) is small at this point. Further inspecting the profile of $K_{s}$, it is found 

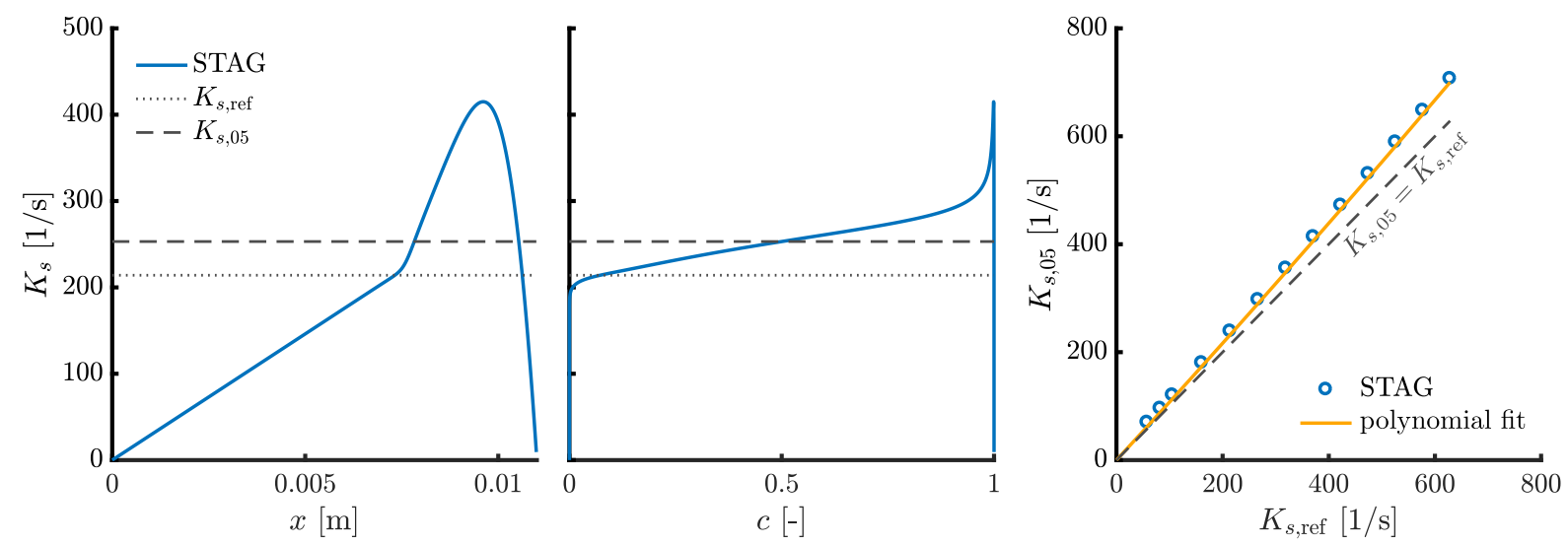

Figure 5: Strain rate $K_{s}$ for a lean $\mathrm{H}_{2}$-air stagnation flame with $K_{s, \text { ref }}=214 \mathrm{~s}^{-1}$ versus the physical space coordinate (left) and the normalized progress variable $c$ (middle). For the premixed flamelet model $K_{s, 05}$ is prescribed which is expressed as a function of $K_{s, \text { ref }}$ to facilitate a comparison of the premixed flamelet model to experiments (right).

that $K_{s}$ increases from the unburned to the burned edge of the flame. In $c$-space, $K_{s}$ is almost linear for $0.1<c<0.9$, but it exhibits steep gradients towards the boundaries. In the following it will be shown that the premixed flamelet model yields accurate results for stagnation flames if the profile of $K_{s}$ is approximated by a representative value. Therefore, the reference strain rate $K_{s, 05}$ is introduced which is defined as the strain rate $K_{s}$ evaluated at $c=0.5$. This choice is motivated by the fact that strain should be prescribed at the inner layer of a premixed flame to recover its flame structure accurately [39]. It should be noted that the inner structure of a premixed flame becomes stretched when conditioning on the progress variable [22] which implies that also other choices for fixing the strain rate could be reasonable.

Comparison between experiments and numerical results. Numerical results obtained with the physical space and the progress variable space model are now compared to experiments in terms of $s_{u \text {,ref }}$ and $K_{s, \text { ref }}$. While $s_{u, \text { ref }}$ is readily evaluated from all numerical solutions, $K_{s, \text { ref }}$ is a flow control parameter of the premixed flamelet model and thus it needs to be prescribed. Similarly, $K_{s, 05}$ is inaccessible from experiments. Therefore, $K_{s, \text { ref }}$ and $K_{s, 05}$ are related to each other by a second order polynomial fit through the physical space computations to assign representative strain rates $K_{s, \text { ref }}$ to every premixed flamelet solution, which is shown in Fig. 5 (right).

Figure 6 (left) shows $s_{u \text {,ref }}$ versus $K_{s, \text { ref }}$ for lean $\mathrm{H}_{2}$-air flames $(\varphi=0.35)$ at atmospheric conditions. It contains numerical and experimental data by Vagelopoulos et al. [66] who determined laminar burning velocities with the counterflow twin flame technique. Furthermore, Fig. 6 contains the physical space solution (Eqs. (2))for the stagnation flames (STAG), the corresponding results 

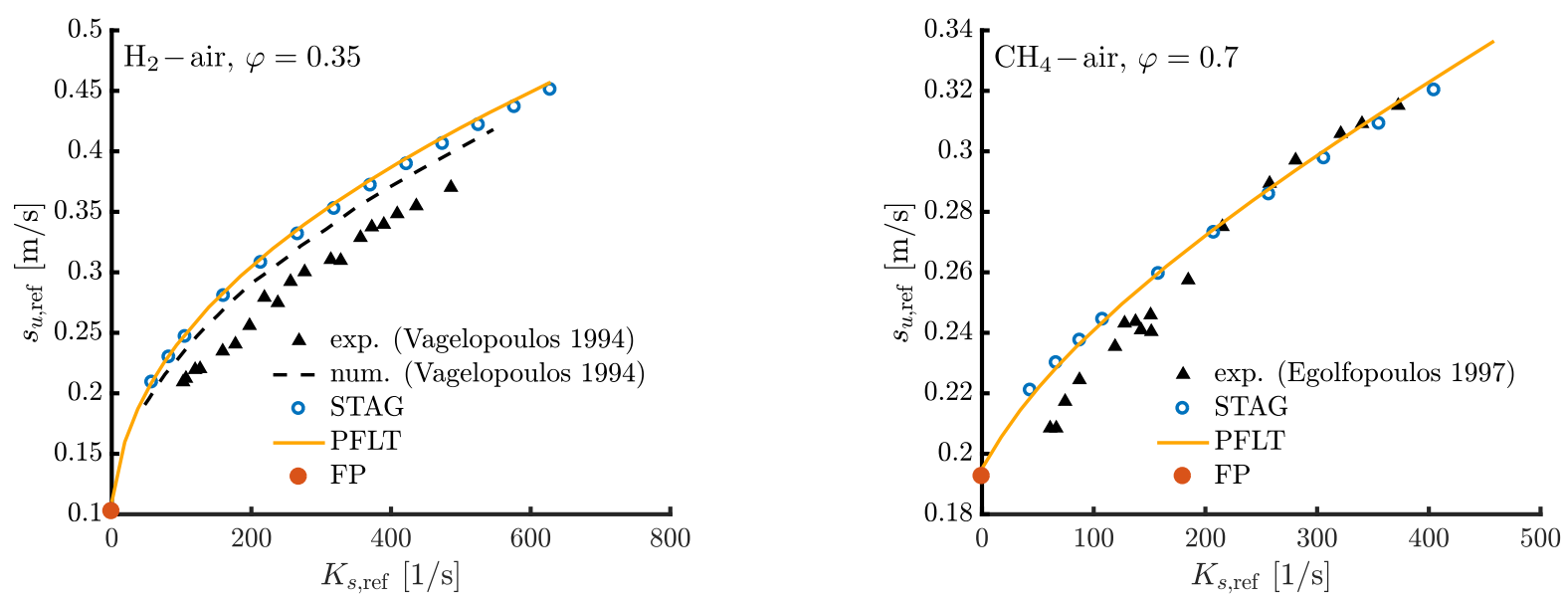

Figure 6: Reference flame speed $s_{u \text {,ref }}$ versus strain rate for atmospheric $\mathrm{H}_{2}$-air $\left(\varphi=0.35\right.$, left) and $\mathrm{CH}_{4}$-air stagnation flames $(\varphi=0.7$, right). Experimental and numerical results by Vagelopoulos et al. [66] and Egolfopoulos et al. 64 are shown in comparison to numerical results obtained from a physical space solution method (STAG) and the premixed flamelet model in progress variable space (PFLT). The unstretched laminar burning velocity evaluated for a freely-propagating flame in physical space is shown as a reference (FP). The progress variable is defined as $Y_{c}=Y_{\mathrm{H}_{2} \mathrm{O}}-Y_{\mathrm{H}_{2}}-Y_{\mathrm{O}_{2}}\left(\mathrm{H}_{2}\right.$-air flames $)$ and $Y_{c}=Y_{\mathrm{CO}_{2}}+Y_{\mathrm{H}_{2} \mathrm{O}}+10 Y_{\mathrm{H}_{2}}-Y_{\mathrm{O}_{2}}\left(\mathrm{CH}_{4}\right.$-flames $)$ in the flamelet calculations.

for the premixed flamelet model (PFLT, Eqs. (22)-(24)) and the unstretched laminar burning velocity obtained for a freely-propagating flame as a reference (FP). As observed from Fig. 6, all the numerical results overpredict the experimental results (including previous simulations reported in Vagelopoulos et al. [66]), however the overall trend is well capured. Notably, the flamelet solutions agree well with the physical space reference solutions of the stagnation flames.

Similarly as for the $\mathrm{H}_{2}$-air flames, Fig. 6 (right) shows $s_{u \text {,ref }}$ versus $K_{s, \text { ref }}$ for lean atmospheric $\mathrm{CH}_{4}$-air flames $(\varphi=0.7)$. The numerical results agree well with the experimental data at strain rates $K_{s, \text { ref }}>200 \mathrm{~s}^{-1}$, while there are deviations for smaller strain rates. Again, the flamelet model recovers the physical space reference solutions well. Keeping in mind that $s_{u}$ scales with $s_{u, \text { ref }}$, these results illustrate that the premixed flamelet model accurately captures the influence of strain on the laminar burning velocity. This is further supported by comparing the profiles of the the temperature, the progress variable gradient, and species mass fractions between the STAG and the PFLT model, which is shown in Fig. 7 for the previously discussed $\mathrm{H}_{2}$-air flames. It is found that the profiles obtained with the physical space reference model are very accurately recovered with the flamelet model for different strain rates. As shown in Fig. 7, this is also the case for highly diffusive species such as $\mathrm{H}_{2}$ and radicals such as $\mathrm{H}$. Similar characteristics are observed for other major and minor species (not shown for brievty). 

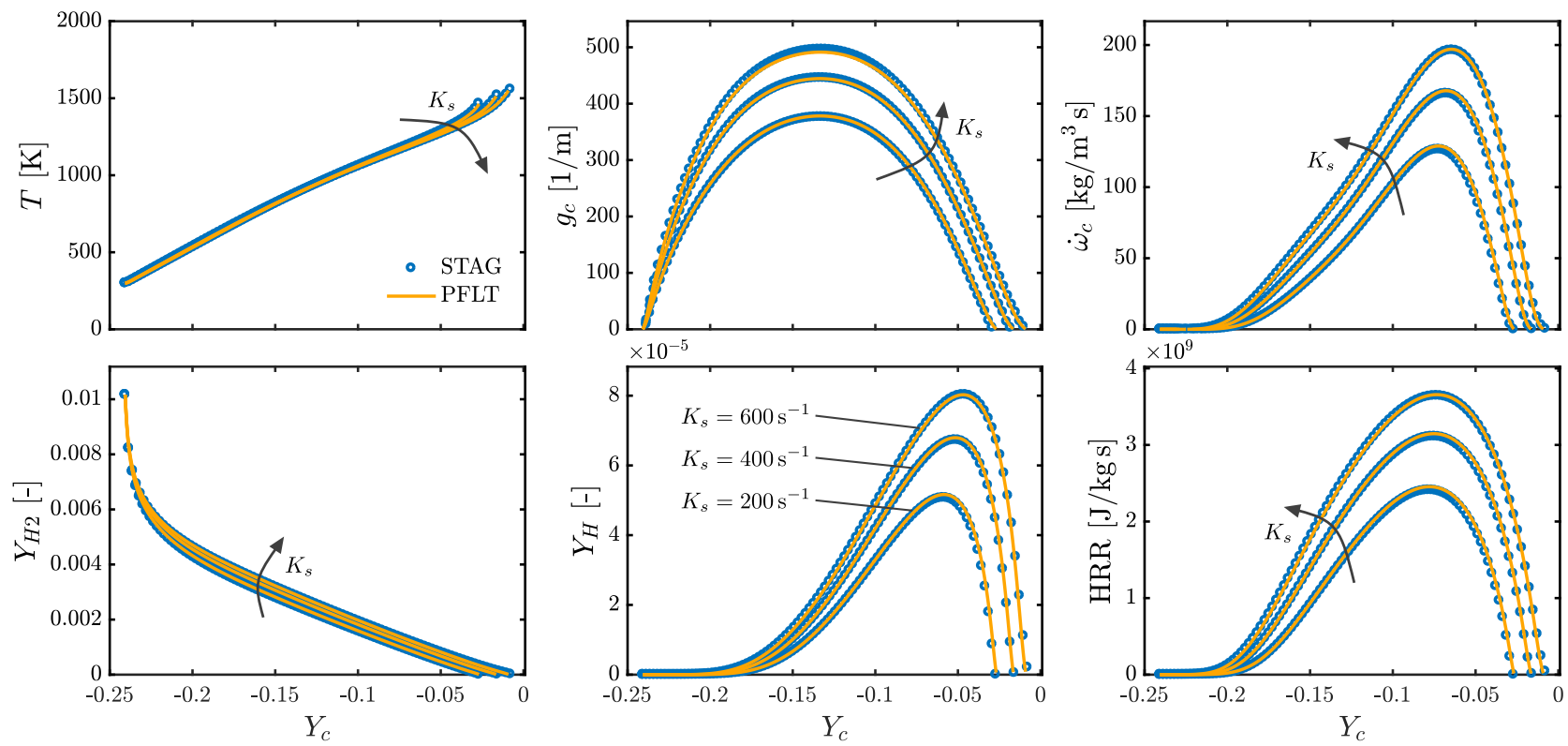

Figure 7: Profiles for the temperature, the progress variable gradient, the progress variable source term, the heat release rate (HRR), and the species mass fractions of $\mathrm{H}_{2}$ and $\mathrm{H}$ for the lean $\mathrm{H}_{2}$-air flames studied by Vagelopoulos et al. 66] (c.f. Fig. 6, left). Results obtained with the physical space model (STAG) are compared to flamelet solutions (PFLT) for three different strain rates $\left(K_{s}=200|400| 600 \mathrm{~s}^{-1}\right)$. The progress variable is defined as $Y_{c}=Y_{\mathrm{H}_{2} \mathrm{O}}-Y_{\mathrm{H}_{2}}-Y_{\mathrm{O}_{2}}$.

Strain-induced effects for premixed flames with Le $<1$. After the comparison to experimental reference data, characteristics of strained premixed flame structures are investigated in more detail with the numerical models. Positive (extensive) strain generally increases gradients in the flame [62], which is properly reflected in the flamelet model, since positive strain acts as a production term for the gradient $g_{c}$, c.f. Eq. 24). Strain thereby inherently promotes diffusive transport of reactants to the reaction zone (proportional to species gradients) but also the heat conduction away from the flame (proportional to temperature gradients). For flames with effective Lewis numbers smaller than unity, e.g. lean $\mathrm{H}_{2}$-air flames $\left(\mathrm{Le}_{\mathrm{H}_{2}} \approx 0.3\right)$, positive strain therefore strengthens the flame [54, 62].

Figure 8 compares three lean $\mathrm{H}_{2}$-air flames computed with physical space solution methods (unstrained: FP, strained: STAG, $K_{s, 05}=0 / 500 / 2000 \mathrm{~s}^{-1}$ ) against corresponding results obtained with the premixed flamelet model. From the right graph it is observed for an unstretched flame that the local equivalence ratio $\varphi$ decreases from the fresh gas mixture (left boundary) before it returns to the original equivalence ratio in the post-oxidation zone (right boundary). The much leaner mixture for intermediate progress variables is explained by the fact that $\mathrm{H}_{2}$ diffuses much faster than other species towards the reaction zone where it is subsequently consumed. For strained flames, it is found that the flame becomes enriched towards the right boundary which is in accordance 

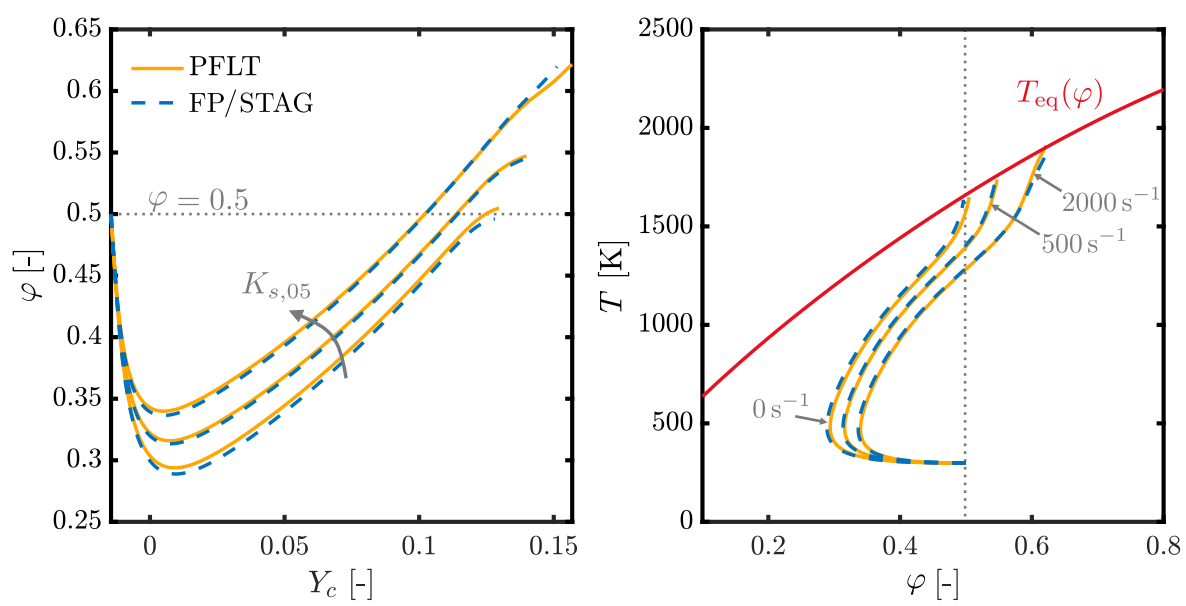

Figure 8: Left: local equivalence ratio versus progress variable for three lean $\mathrm{H}_{2}$-air flames at atmospheric conditions imposing different strain rates $\left(\varphi=0.5, K_{s, 05}=0 / 500 / 2000 \mathrm{~s}^{-1}\right)$. The results are obtained with physical space solvers (FP/STAG) and the premixed flamelet model (PFLT). Right: local temperature versus local equivalence ratio. The solid red line marks the equilibrium temperature $T_{\mathrm{eq}}$ computed for $\mathrm{H}_{2}$-air mixtures as a function of the equivalence ratio $\varphi$. The progress variable is defined as $Y_{c}=Y_{\mathrm{H}_{2} \mathrm{O}}-Y_{\mathrm{H}_{2}}-Y_{\mathrm{O}_{2}}$ in the flamelet calculations.

with the explanation for the strain effect given above.

The right graph of Fig. 8 shows the local temperature $T$ as a function of the local equivalence ratio $\varphi$. Furthermore, the equilibrium temperature $T_{\text {eq }}$ is depicted, which is computed for $\mathrm{H}_{2}$-air mixtures as a function of $\varphi$. It is observed that unstrained and strained flames reach a local chemical equilibrium in the post oxidation zone, since the flame temperature eventually reaches a point on the profile of $T_{\text {eq }}(\varphi)$. It is found that positively strained flames with Le $<1$ reach a higher flame temperature than the adiabatic flame temperature of their respective fresh gas mixture due to local fuel enrichment. This strain-induced effect is sometimes termed hot spot or super-adiabatic and can also be observed in turbulent combustion [50 52] (curvature can have similar effects). The comparison above further confirms that the expansion of the $Y_{c}$-space (local enrichment effect) is correctly captured by the flamelet model and the right boundary eigenvalue of the $Y_{c}$-space is well-predicted.

Extinction limits for premixed flames with Le $<1$. Besides positive strain rates, the flamelet model in progress variable space allows prescribing negative strain rates. This is demonstrated by examining extinction limits for both, positive and negative strain rates, next. The effect of strain on the flame structure is characterized considering quantities at the inner layer, which can be defined by the position of the maximum heat release rate [36, 39]. Note that the reference quantity $s_{u, \text { ref }}$ is not suitable for this analysis since it not only depends on strain, but also on thermal expansion 
which complicates a proper assessment of strain-induced effects [36].
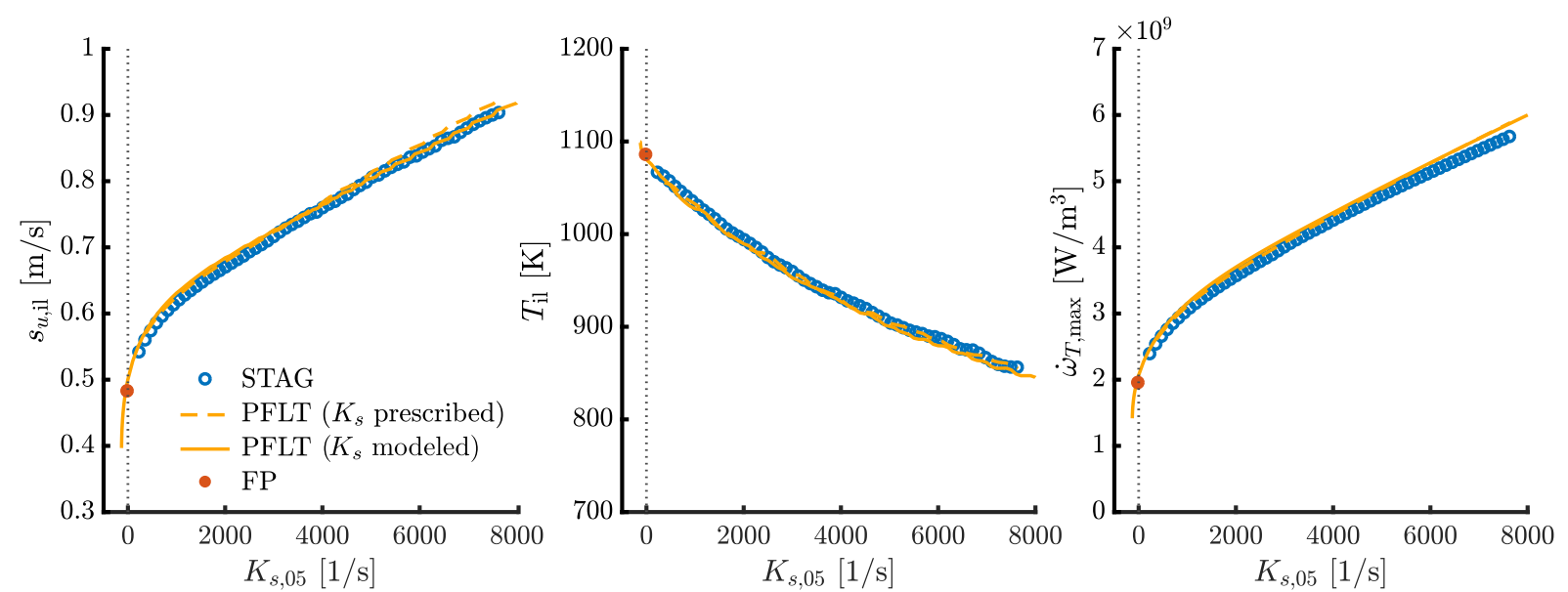

Figure 9: Inner layer quantities: burning velocity $s_{u, \text { il }}$, temperature $T_{\mathrm{il}}$ and maximum heat release rate $\dot{\omega}_{T, \max }$ as functions of strain for lean $\mathrm{H}_{2}$-air flames $\left(\varphi=0.5, T_{u}=298 \mathrm{~K}\right)$. The progress variable is defined as $Y_{c}=$ $Y_{\mathrm{H}_{2} \mathrm{O}}-Y_{\mathrm{H}_{2}}-Y_{\mathrm{O}_{2}}$ in the flamelet calculations.

Figure 9 shows the numerical results obtained for lean $\mathrm{H}_{2}$-air flames $(\varphi=0.5)$ towards higher positive strain rates and also for negative strain rates. Besides results for the physical space stagnation flame model (STAG, blue circles) and the premixed flamelet model with $K_{s}$ approximated by a representative value (PFLT, solid line), the latter has also been computed with the full strain rate profile extracted from corresponding STAG solutions (PFLT, dashed line). Furthermore, numerical results for unstrained flames (FP, red circle) are given for orientation.

The strain-induced strengthening of flames with Le $<1$ is reconfirmed considering the burning velocity at the inner layer $s_{u \text {,il }}$ and the maximum heat release rate $\dot{\omega}_{T, \max }$ in Fig. 9 (left and right plot, respectively) which both increase with positive strain. The inner layer temperature $T_{\mathrm{il}}$ decreases for $K_{s, 05}>0$ (Fig. 9, mid plot) which implies that the maximum heat release becomes shifted to lower temperatures. As long as solutions for the physical space model exist, the inner layer quantities are well reproduced by the premixed flamelet model (Eqs. (22)-(24)). The flamelet model with the prescribed strain profile virtually yields the same result compared to the model with a representative constant strain rate.

It is found that the stagnation flame extinguishes at $K_{s, 05}=7644 \mathrm{~s}^{-1}$ while the premixed flamelet model predicts solutions also for significantly higher strain rates (not explicitly shown). This is due to the fact that flames with Le $<1$ do not become extinguished due to positive strain effects (which strengthen the flame), but due to incomplete reactions, when they are pushed against 
a wall or stagnation surface. In his book, Law [54] therefore calls stagnation flames restrained. Approaching the stagnation surface, the thickness of the flame becomes smaller leading to reduced residence times of reactants. Increasing the strain rate, restrainment initially appears as an effect in the post-oxidation zone, where the thermochemical state does not reach equilibrium conditions anymore (lowered temperatures). Eventually increasing strain above a critical limit, residence times of reactants are so small that the flame becomes extinguished. On the contrary, the premixed flamelet model does not account for restrainment, since both boundaries are infinitely removed from the reaction zone of the premixed flame. Thus, flamelet solutions can be found for much higher strain rates and computations were aborted at $K_{s, 05}=15000 \mathrm{~s}^{-1}$. For modeling turbulent flames, which can exhibit very large strain rates [37], these characteristics of the premixed flamelet model could become advantageous, because highly strained canonical flames can be considered aside from artefacts induced by a given physical space configuration.

At zero strain (vertical dotted line in Fig. 9p, the premixed flamelet model recovers the characteristics of the freely-propagating flame model $(\mathrm{FP})$. For $K_{s, 05}<0$, it is found that the lean $\mathrm{H}_{2}$-air flames show a clear extinction limit since negative strain weakens the flame for Le $<1$. The negative strain extinction limit is determined as $K_{s}=-130 \mathrm{~s}^{-1}$ for which the profiles of $s_{u, \text { il }}$ and $\dot{\omega}_{T, \max }$ versus $K_{s, 05}$ become almost singular. To the authors' knowledge, this negative strain extinction limit is inassessible with conventional low-dimensional flame solvers.

Extinction limits for premixed flames with Le $>1$. Opposed to the previously discussed $\mathrm{H}_{2}$-air flames, lean $\mathrm{C}_{2} \mathrm{H}_{5} \mathrm{OH}$-air flames exhibit an effective Lewis number larger than unity $\left(\mathrm{Le}_{\mathrm{C}_{2} \mathrm{H}_{5} \mathrm{OH}} \approx 1.6\right)$ and positive strain weakens these flames [54, 62]. This strain-induced effect is displayed in Fig. 10 which shows the stagnation flame results obtained with the physical space solver (STAG) compared to flamelet solutions (PFLT, with constant $K_{s}$ ), and freely-propagating flame solutions for reference. Also for the $\mathrm{C}_{2} \mathrm{H}_{5} \mathrm{OH}$-air flames $T_{\mathrm{il}}$ (Fig. 10, mid) decreases with positive strain, indicating a shift of the maximum heat release to lower temperatures. However, it is observed that the inner layer burning velocity $s_{u, \text { il }}$ (left) and the maximum heat release rate $\dot{\omega}_{T, \text { max }}$ (right) both decrease for $K_{s, 05}>0$. Consequently, a positive strain extinction limit can be identified for lean $\mathrm{C}_{2} \mathrm{H}_{5} \mathrm{OH}$-air flames, which is predicted as $930 \mathrm{~s}^{-1}$ with the physical space STAG model and $902 \mathrm{~s}^{-1}$ with the PFLT model (deviation: $3 \%$ ). Keeping in mind that constant strain rates are prescribed for the flamelet model, the small overall differences between the two models are acceptable. 

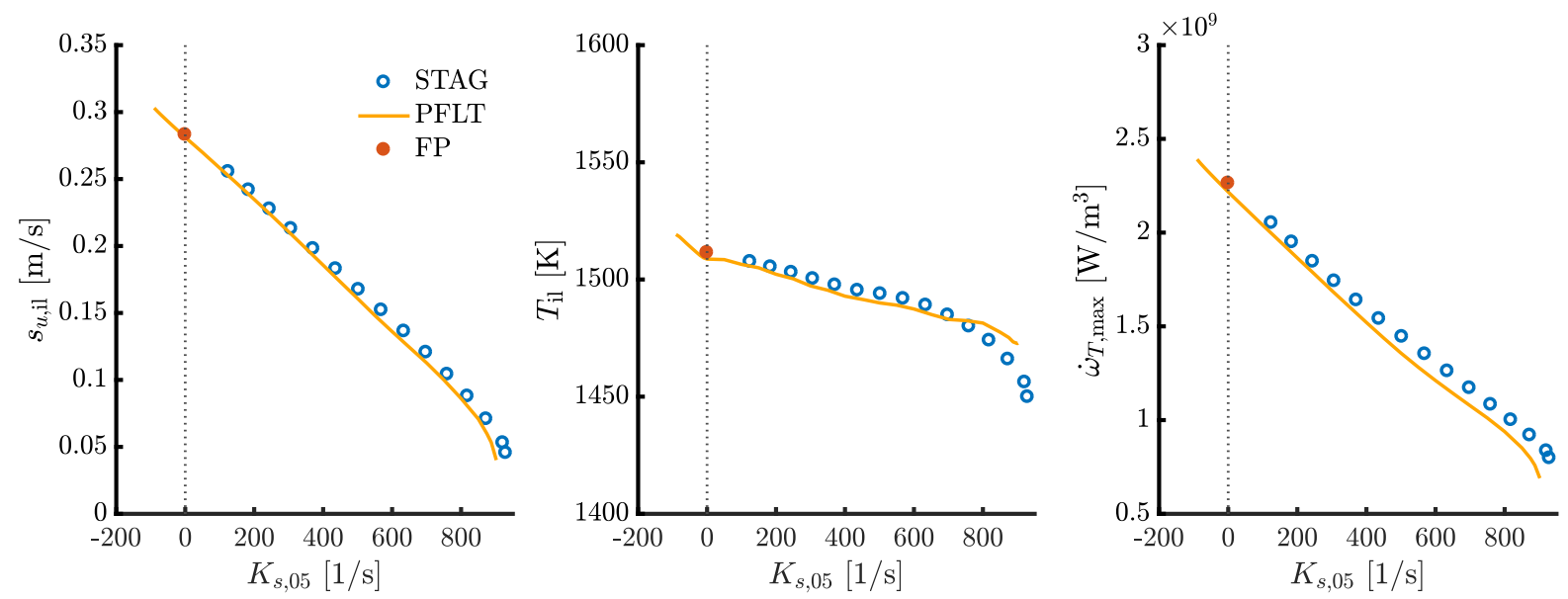

Figure 10: Inner layer quantities burning velocity $s_{u, \text { il }}$, temperature $T_{\text {il }}$ and maximum heat release rate $\dot{\omega}_{T, \max }$ as functions of strain for lean $\mathrm{C}_{2} \mathrm{H}_{5} \mathrm{OH}$-air flames $\left(\varphi=0.7, T_{u}=363 \mathrm{~K}\right)$. The progress variable is defined as $Y_{c}=Y_{\mathrm{CO}_{2}}+Y_{\mathrm{H}_{2} \mathrm{O}}+10 Y_{\mathrm{H}_{2}}-Y_{\mathrm{O}_{2}}$ in the flamelet calculations.

Similar to $\mathrm{H}_{2}$-air flames, $\mathrm{C}_{2} \mathrm{H}_{5} \mathrm{OH}$-air flames can tolerate a certain level of negative strain. It is found from Fig. 10, that the maximum flame temperature and the maximum heat release both increase with negative strain rates, which is contrary to $\mathrm{H}_{2}$-air flames. The negative strain extinction limit is determined as $K_{s, 05}=-90 \mathrm{~s}^{-1}$, which appears abrupt, since none of the quantities depicted in Fig. 10 visually indicates a limit. However, below this level no flamelet solution could be obtained and it remains an open question wether this is a physical effect or a numerical artifact.

The results presented in this section confirm that the premixed flamelet model captures strain effects on premixed flame structures accurately. It is further demonstrated that prescribing strain by representative values in progress variable space is a sufficiently good model, which is a valuable insight for flamelet tabulation strategies.

\subsubsection{Tubular stagnation flames}

Figure 11 shows the schematic of a tubular burner. A combustible fresh gas mixture is issued inwardly from a porous tube and forms a cylindrically symmetric stagnation flow. Eventually, gases exit the burner in the axial direction. With this burner setup a stationary tubular flame is established which is stretched and curved at the same time. Increasing the inlet velocity, the flame is pushed towards the stagnation line and flame strain and curvature are both increased.

Physical space model. In physical space, the tubular burner can be described by the equation set published by Wang et al. [67], which is similar to the model for stagnation flames. From a similarity transformation of the governing equations in physical space a one-dimensional equation set with 


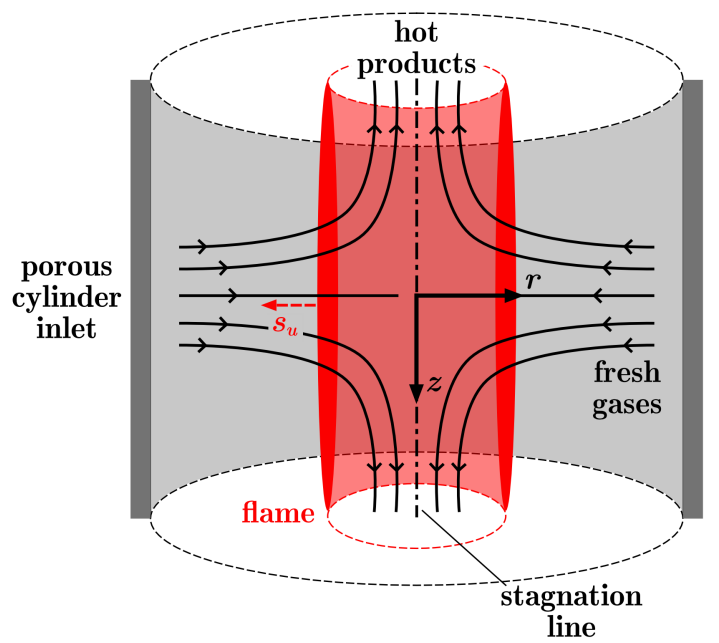

Figure 11: Schematic of a tubular burner in which a premixed tubular stagnation flame is established.
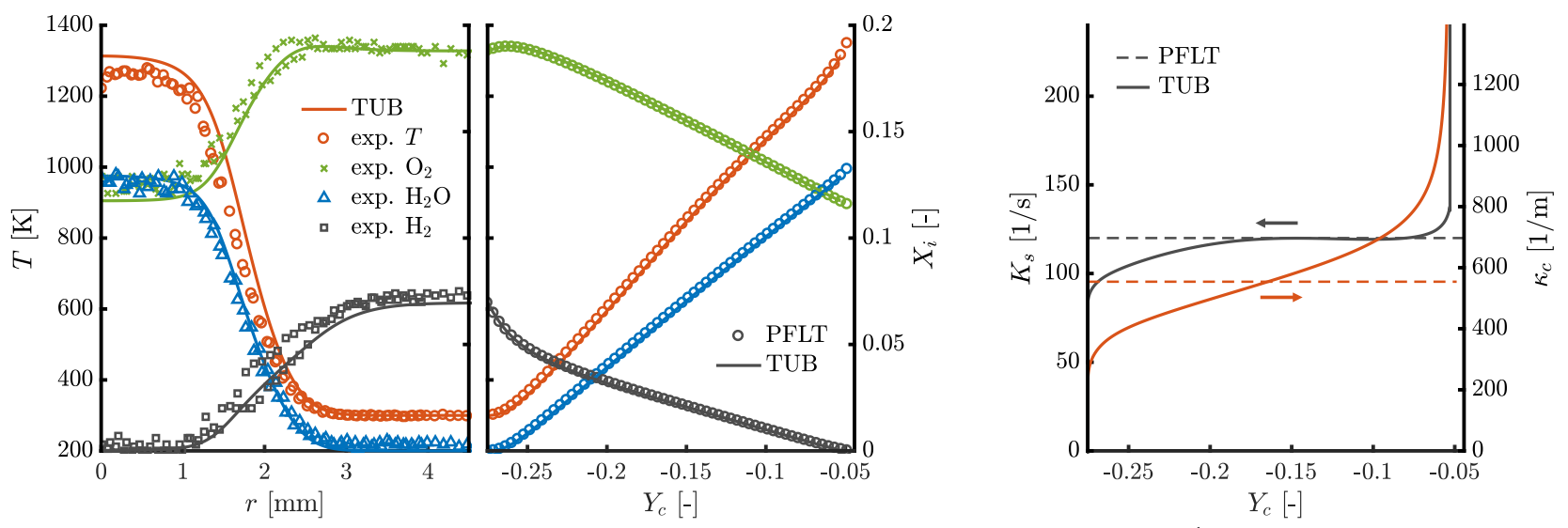

Figure 12: Flame structure of a lean $\mathrm{H}_{2}$-air tubular flame $\left(\varphi=0.175, K_{s, r e f}=145 \mathrm{~s}^{-1}\right)$. Left: Comparison of the 1D flame simulation data for the tubular burner (TUB) with corresponding experimental data by Hu et al. [68]. Middle: Comparison of the physical space simulation data (TUB) to the results obtained with the premixed flamelet model (PFLT). Right: Comparison of the extracted profiles for strain $K_{s}$ and curvature $\kappa_{c}$ from the physical space numerical solution to the prescribed profiles for the premixed flamelet model. The progress variable is defined as $Y_{c}=Y_{\mathrm{H}_{2} \mathrm{O}}-Y_{\mathrm{H}_{2}}-Y_{\mathrm{O}_{2}}$ in the flamelet calculations.

respect to the radial coordinate $r$ is obtained. This model will be used to validate the flamelet model in terms of curvature-affected premixed flames.

Comparison between experiments and numerical results. For the tubular burner, experimental data of temperature and major species concentrations are available from the work by $\mathrm{Hu}$ et al. [68]. Figure 12 shows the profiles of temperature, $\mathrm{O}_{2}, \mathrm{H}_{2} \mathrm{O}$ and $\mathrm{H}_{2}$ for an ultra lean $\mathrm{H}_{2}$-air tubular flame $\left(\varphi=0.175, K_{s, r e f}=145 \mathrm{~s}^{-1}\right)$. As observed from the left graph, the position and the structure of the flame are well captured by the physical space numerical solution. While the temperature is slightly overpredicted, the numerical results recover the species profiles well. In the mid-graph the physical space numerical solution is compared to the progress variable space numerical solution 
obtained with the flamelet model. It is found that the flamelet solution is essentially equivalent to the physical space solution. A small difference is found at the right boundary (post oxidation zone) which extends further for the flamelet model. Similar to the stagnation flame, this characteristic is attributed to the restrainment of the physical space flame configuration at the stagnation point. To capture both strain and curvature effects with the premixed flamelet model, representative values for $K_{s}$ and $\kappa_{c}$ were determined from the physical space solution at $c=0.5$ and prescribed for the flamelet model.

\subsubsection{Spherical expanding flames}

The spherical expanding flame is established by igniting an initially quiescent gas mixture with a spark from which subsequently an outwardly propagating flame develops. For controlling the flame, experiments are carried out in closed vessels which further allow studying flame propagation under high pressures. The flame evolution is usually recorded by Schlieren or shadow photography using high speed cameras. With this technique, the burning velocity can be determined from the observation of the flame speed together with the unburned and burned gas density ratio [49] or directly from the difference of the propagation speed of the flame $s_{f}$ and the fresh gas velocity $u_{g}$ [49, 61, 69, 70] according to Eq. (35). Figure 13 shows a schematic of a spherical expanding flame.

The flame propagates outwardly as indicated by the red arrows and it is further pushed in the same

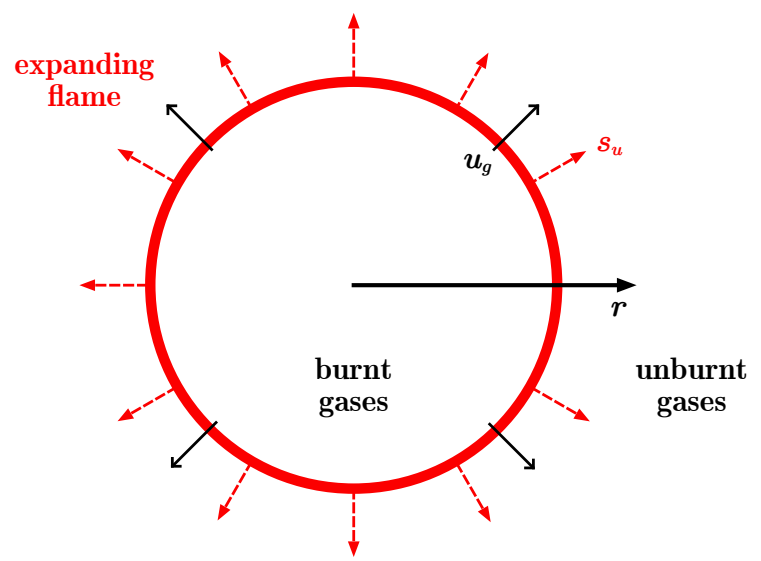

Figure 13: Schematic of a spherical expanding flame.

direction due to thermal expansion of the reaction products. This thermal expansion causes an entrainment of cold unburned gas by the flame which can be measured as the velocity of unburnt gases $u_{g}$ ahead of the flame front [61, 69]. Due to symmetry, the flame can also be described by a 
set of time-dependent and spatially one-dimensional differential equations [71] (with respect to the radial coordinate $r$ ).

Flame stretch and curvature. The flame's surface increases continuously with time since it is curved and it moves outwardly with the flame speed $s_{f}$. Consequently the flame front becomes stretched. The overall stretch rate of the spherical expanding flame front is determined as [35]

$$
K=\frac{2}{r} \frac{\mathrm{d} r}{\mathrm{~d} t}=\frac{2}{r} s_{f}=\kappa_{c} s_{f}
$$

where the curvature of the flame front $\kappa_{c}=2 / r$ evolves with time. When computing spherical expanding flames with the premixed flamelet model, strain and curvature need to be prescribed. While the definition of the curvature is readily available from the flame geometry, the premixed flamelet model further requires the strain rate imposed by the flow which is defined according to Eq. (25)

$$
K_{s}=K-s_{u} \kappa_{c} \stackrel{36}{=}-\left(s_{f}+s_{u}\right) \kappa_{c} \stackrel{35}{=}-u_{g} \kappa_{c} .
$$

Note that $u_{g}$ is negative in this equation due to the convention $u_{g}=\mathbf{n}_{c} \cdot \mathbf{u}$. For the spherical expanding flame $\mathbf{u}$ is directed opposite to $\mathbf{n}_{c}$, thus, the strain rate $K_{s}$ is positive which is consistent with the literature. Furthermore, in the above relation the flame displacement speed $s_{d}$ and the flame's burning velocity $s_{u}$ are set equal which is valid only at the unburnt edge of the flame as outlined in Sec. 5.2. For spherical expanding flames usually $s_{f}$ is reported as a function of $K$ which allows to recompute the flame's curvature according to $\kappa_{c}=K / s_{f}$. However, the premixed flamelet model can only be applied if also the gas velocity $u_{g}$ is reported from the experiments. Otherwise, imposed strain by the flow $K_{s}=-u_{g} \kappa_{c}$ and strain due to the propagation of the flame itself $\left(s_{u} \kappa_{c}\right.$, which is a flame response) cannot be separated. Suitable reference data has been reported by multiple researchers for hydrogen and hydrocarbon flames [61, 69, 70, 72].

Comparison between experiments and numerical results. Figure 14 shows experimental reference data by Varea et al. [70] for lean $\mathrm{H}_{2}$-air flames together with results obtained with the premixed flamelet model. Similarly as for planar and tubular stagnation flames, strain and curvature are prescribed as representative constants which were determined with average values from the experiments from Eqs. (36) and (37). Overall the agreement between experiments and numerical results for the 

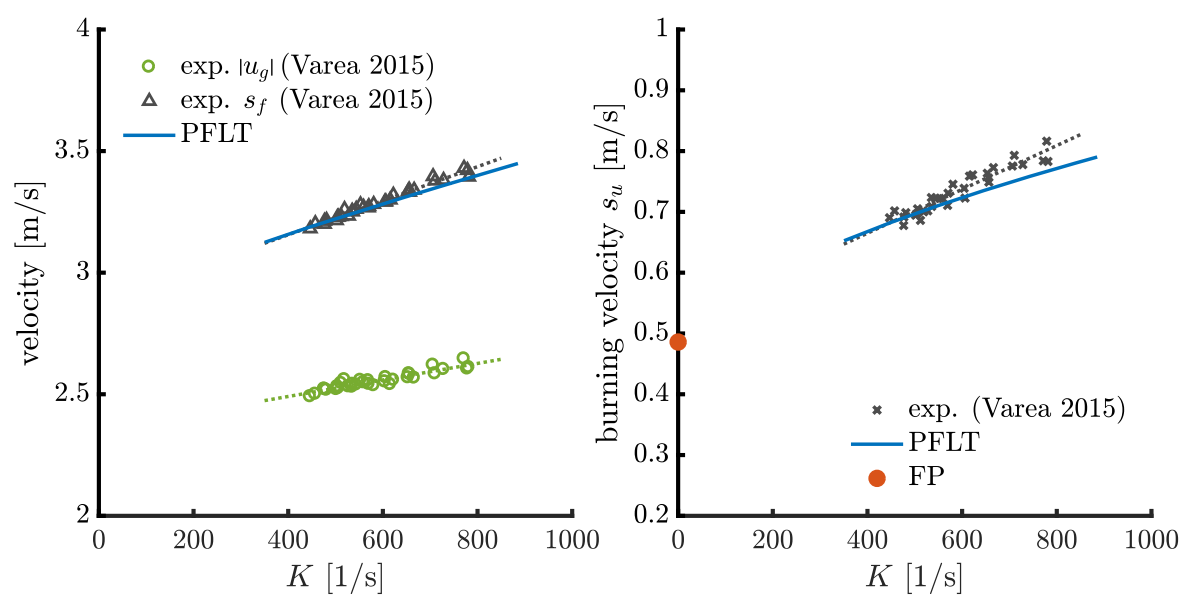

Figure 14: Left: Measurements of the apparent flame speed $s_{f}$ and the velocity of the fresh gases $u_{g}$ for a spherical expanding flame by Varea et al. [70] $\left(\mathrm{H}_{2}\right.$-air, $\left.\varphi=0.5\right)$. Numerical results are obtained with the premixed flamelet model (PFLT, solid line) and the dotted lines mark a linear regression of the experimental data. Right: comparison of burning velocities evaluated from the experimental data and the premixed flamelet model. The laminar burning velocity for a freely-propagating flame is shown for reference (FP). The progress variable is defined as $Y_{c}=Y_{\mathrm{H}_{2} \mathrm{O}}-Y_{\mathrm{H}_{2}}-Y_{\mathrm{O}_{2}}$ in the flamelet calculations.

stretched laminar burning velocity (Fig. 14, right graph) is good with only slight deviations towards higher stretch rates. However, these deviations are less prominent when comparing the overall flame speed $s_{f}$ (Fig. 14, left graph).

Similar results are obtained for lean $\mathrm{CH}_{4}$-air flames for which experimental data by Varea et al. 61] and corresponding flamelet solutions are shown in Fig. 15. The overall trend and magnitude
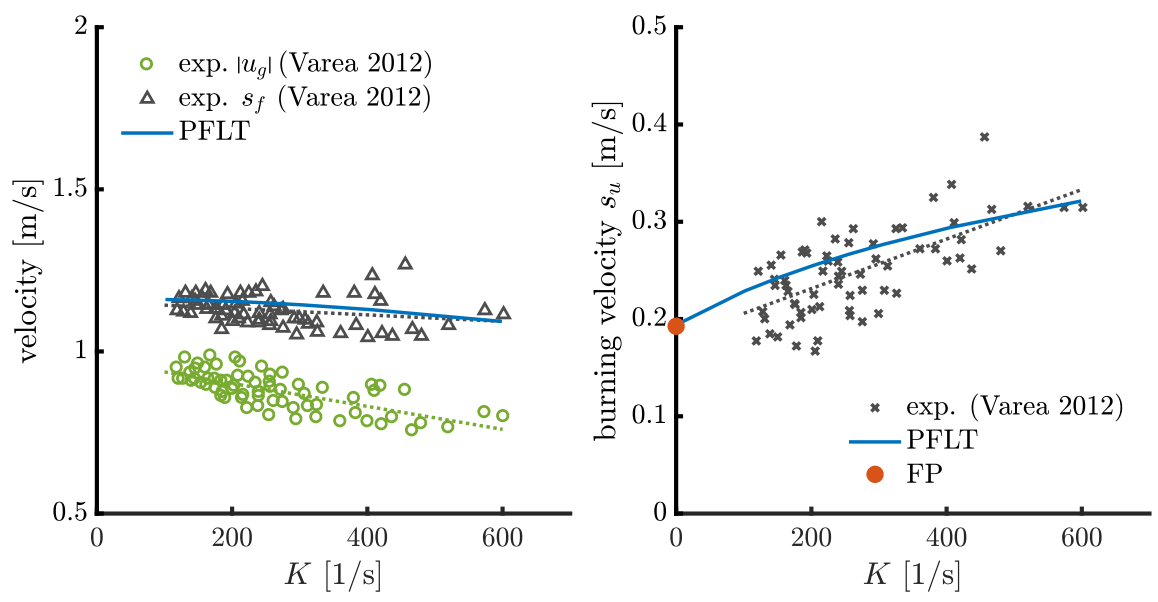

Figure 15: Left: Measurements of the apparent flame speed $s_{f}$ and the velocity of the fresh gases $u_{g}$ for a spherical expanding flame by Varea et al. 61] $\left(\mathrm{CH}_{4}\right.$-air, $\left.\varphi=0.7\right)$. Numerical results are obtained with the premixed flamelet model (PFLT, solid line) and the dotted lines mark a linear regression of the experimental data. Right: comparison of burning velocities evaluated from the experimental data and the premixed flamelet model. The laminar burning velocity for a freely-propagating flame is shown for reference (FP). The progress variable is defined as $Y_{c}=Y_{\mathrm{CO}_{2}}+Y_{\mathrm{H}_{2} \mathrm{O}}+10 Y_{\mathrm{H}_{2}}-Y_{\mathrm{O}_{2}}$ in the flamelet calculations. 
for the stretched laminar burning velocity (right graph) is well captured by the flamelet model with slightly overpredicted values for stretch rates between 150 to $400 \mathrm{~s}^{-1}$. However, the comparison of the flame speed $s_{f}$ (Fig. 15, left graph) shows that the deviation between numerical result and linear regression of the experimental data remains small.

Only few information is necessary to reproduce magnitude and trend of the experimentally determined burning velocities. This underlines the high flexibility of the premixed flamelet model and confirms that the model captures the interplay of strain, curvature, and unsteadiness. Given a pair of parameters, $K_{s}$ and $\kappa_{c}$, one computation with the flamelet model yields the premixed flame response, e.g. in terms of its flame structure and burning velocity. With few exceptions [39], most physical space models compute the whole transient evolution of the spherical expanding flame (until a self-similar state) before this information becomes available.

\section{Summary and conclusions}

A self-contained premixed flamelet model was presented which describes premixed flames in progress variable space. The model is based on flamelet equations for temperature, species mass fractions, and the gradient of the progress variable. The latter establishes a direct link of the flamelet structure to the fundamental flame parameters strain and curvature. As already shown in an earlier work [22], treating the progress variable gradient as a dependent variable resolves a severe limitation of flamelet modeling in scalar space. Similar previous flamelet formulations [21, 23, 53] required a closure for both the shape and the magnitude of the gradient, for which a generic profile does not exist in case of premixed combustion. With the novel approach, an effective closure of the flamelet equations was obtained by prescribing the flamelet parameters strain and curvature through representative constant values.

The predictive capabilities of the new method were demonstrated for a constant pressure ignition problem and three canonical flame configurations: the stagnation flame, the tubular flame and the spherical expanding flame. Different models are necessary to describe the aforementioned canonical combustion configurations in the physical space, but all of them can be described using a single premixed flamelet model in progress variable space. A combination of physical space reference solutions and experimental measurements from the literature was used for the validation. Very accurate results were found for constant pressure ignition, flame structures, burning velocities, and 
flame extinction. Furthermore, the premixed flamelet model allowed to capture strain-induced hot spots and even negative strain effects. With few exceptions [39, 40], the latter remains inaccessible for conventional low-dimensional flame solvers.

Multiple future applications of the premixed flamelet model are conceivable. Its generic parametrization allows analyses of flame structures which do not have a direct canonical flame counterpart in the physical space. This facilitates parametric studies well beyond the limits of, for instance, tubular flames or stagnation flames in terms of curvature and strain. With this, the model is well suited for tabulated chemistry approaches in a CFD context since these conditions have been shown to be relevant for turbulent combustion. Further, it can be used for numerically assisted interpretation of experimental data. The determination of the laminar burning velocity from experiments of stretched premixed flames usually relies on extrapolation procedures to zero stretch [36]. Extrapolation methods could be complemented using the work reported in this paper, since it allows for a continuous representation of the burning velocity over the full stretch range.

\section{Acknowledgments}

Financial support is kindly acknowledged from the German Research Foundation (DFG) in the Project HA 4367/5-1.

\section{References}

[1] N. Peters, Multiscale combustion and turbulence, Proc. Combust. Inst. 32 (2009) 1-25.

[2] R. S. Barlow, J. H. Frank, A. N. Karpetis, J.-Y. Chen, Piloted methane/air jet flames: Transport effects and aspects of scalar structure, Combust. Flame 143 (2005) 433-449.

[3] A. Liñán, The asymptotic structure of counterflow diffusion flames for large activation energies, Acta Astronautica (1974) 1007-1039.

[4] A. Liñán, D. Martínez-Ruiz, A. L. Sánchez, J. Urzay, Regimes of spray vaporization and combustion in counterflow configurations, Combust. Sci. Tech. 187 (2015) 103-131.

[5] N. Peters, Laminar diffusion flamelet models in non-premixed turbulent combustion, Prog. Energy Combust. Sci. 10 (1984) 319-339.

[6] N. Peters, Laminar Flamelet Concepts in Turbulent Combustion, Symp. (Int.) Combust. 21 (1988) 1231-1250. 
[7] D. Bradley, L. K. Kwa, A. K. C. Lau, M. Missaghi, S. B. Chin, Laminar flamelet modeling of recirculating premixed methane and propane-air combustion, Combust. Flame 71 (1988) $109-122$.

[8] O. Gicquel, N. Darabiha, D. Thévenin, Laminar premixed hydrogen/air counterflow flame simulations using flame prolongation of ILDM with differential diffusion, Proc. Combust. Inst. 28 (2000) $1901-1908$.

[9] J. A. van Oijen, F. A. Lammers, L. P. H. de Goey, Modeling of complex premixed burner systems by using flamelet-generated manifolds, Combust. Flame 127 (2001) 2124-2134.

[10] A. Y. Klimenko, B. R. W, Conditional moment closure for turbulent combustion, Prog. Energ. Combust. Sci. 25 (1999) $595-687$.

[11] S. Pope, PDF methods for turbulent reactive flows, Prog. Energy Combust. Sci. 11 (1985) $119-192$.

[12] W. Kollmann, The pdf approach to turbulent flow, Theor. and Comp. Fluid Dynamics 1 (1990) 349-285.

[13] D. C. Haworth, Progress in probability density function methods for turbulent reacting flows, Prog. Energy Combust. Sci. 36 (2010) 168-259.

[14] R. W. Bilger, S. H. Starner, R. J. Kee, On reduced mechanisms for methane/air combustion in nonpremixed flames, Combust. Flame 80 (1990) 135-149.

[15] H. Pitsch, N. Peters, A consistent flamelet formulation for non-premixed combustion considering differential diffusion effects, Combust. Flame 114 (1998) 26 - 40.

[16] N. Peters, Turbulent Combustion, Cambridge University Press, 2000.

[17] C. Felsch, M. Gauding, C. Hasse, S. Vogel, N. Peters, An extended flamelet model for multiple injections in di diesel engines, Proc. Combust. Inst 32 (2009) 2775-2783.

[18] Y. Xuan, G. Blanquart, M. E. Mueller, Modeling curvature effects in diffusion flames using a laminar flamelet model, Combust. Flame 161 (2014) 1294 - 1309.

[19] A. Scholtissek, W. L. Chan, H. Xu, F. Hunger, H. Kolla, J. H. Chen, M. Ihme, C. Hasse, A multi-scale asymptotic scaling and regime analysis of flamelet equations including tangential diffusion effects for laminar and turbulent flames, Combust. Flame 162 (2015) 1507-1529.

[20] A. D. Weiss, M. Vera, A. Liñán, A. L. Sánchez, F. A. Williams, A novel formulation for unsteady counterflow flames using a thermal-conductivity-weighted coordinate, Combust. 
Theory Modelling 22 (2018) 185-201.

[21] G. Lodier, L. Vervisch, V. Moureau, P. Domingo, Composition-space premixed flamelet solution with differential diffusion for in situ flamelet-generated manifolds, Combust. Flame 158 (2011) $2009-2016$.

[22] A. Scholtissek, P. Domingo, L. Vervisch, C. Hasse, A self-contained progress variable space solution method for thermochemical variables and flame speed in freely-propagating premixed flamelets, Proc. Combust. Inst. (2019).

[23] P.-D. Nguyen, L. Vervisch, V. Subramanian, P. Domingo, Multidimensional flamelet-generated manifolds for partially premixed combustion, Combust. Flame 157 (2010) 43 - 61.

[24] E. Knudsen, H. Pitsch, Capabilities and limitations of multi-regime flamelet combustion models, Combust. Flame 159 (2012) 242-264.

[25] M. Ihme, L. Shunn, J. Zhang, Regularization of reaction progress variable for application to flamelet-based combustion models, J. Comput. Phys. 231 (2012) 7715-7721.

[26] Y.-S. Niu, L. Vervisch, P. D. Tao, An optimization-based approach to detailed chemistry tabulation: Automated progress variable definition, Combust. Flame 160 (2013) 776-785.

[27] U. Prüfert, S. Hartl, F. Hunger, D. Messig, M. Eiermann, C. Hasse, A constrained control approach for the automated choice of an optimal progress variable for chemistry tabulation, Flow, Turbulence and Combustion 94 (2015) 593-617.

[28] J. A. van Oijen, A. Donini, R. J. M. Bastiaans, J. H. M. ten Thije Boonkkamp, L. P. H. de Goey, State-of-the-art in premixed combustion modeling using flamelet generated manifolds, Prog. Energy Combust. Sci. 57 (2016) $30-74$.

[29] M. Matalon, On flame stretch, Combust. Sci. Technol. 31 (1983) 169-181.

[30] F. A. Williams, A review of some theoretical considerations of turbulent flame structure, AGARD Conference Proceeding, 1975 (1975).

[31] P. Clavin, G. Joulin, Premixed flames in large scale and high intensity turbulent flow, J. Phys. Lett. 44 (1983) 1-12.

[32] S. Chung, C. Law, An invariant derivation of flame stretch, Combust. Flame 55 (1984) 123 125.

[33] C. Law, Dynamics of stretched flames, Symp. (Int.) Combust. 22 (1989) 1381-1402.

[34] L. P. H. de Goey, J. H. M. ten Thije Boonkkamp, A mass-based definition of flame stretch for 
flames with finite thickness, Combust. Sci. Technol. 122 (1997) 399-405.

[35] C. Law, C. Sung, Structure, aerodynamics, and geometry of premixed flamelets, Prog. Energy Combust. Sci. 26 (2000) $459-505$.

[36] F. Egolfopoulos, N. Hansen, Y. Ju, K. Kohse-Höinghaus, C. Law, F. Qi, Advances and challenges in laminar flame experiments and implications for combustion chemistry, Prog. Energy Combust. Sci. 43 (2014) 36-67.

[37] G. Fru, G. Janiga, D. Thévenin, Impact of volume viscosity on the structure of turbulent premixed flames in the thin reaction zone regime, Flow Turbul. Combust. 88 (2012) 451-478.

[38] A. Scholtissek, F. Dietzsch, M. Gauding, C. Hasse, In-situ tracking of mixture fraction gradient trajectories and unsteady flamelet analysis in turbulent non-premixed combustion, Combust. Flame 175 (2017) 243-258.

[39] G. R. A. Groot, J. A. van Oijen, L. P. H. de Goey, K. Seshadri, N. Peters, The effects of strain and curvature on the mass burning rate of premixed laminar flames, Combust. Theor. Model. 6 (2002) 675-695.

[40] J. A. M. de Swart, R. J. M. Bastiaans, J. A. van Oijen, L. P. H. de Goey, R. S. Cant, Inclusion of preferential diffusion in simulations of premixed combustion of hydrogen/methane mixtures with flamelet generated manifolds, Flow, Turbulence and Combustion 85 (2010) 473-511.

[41] W. Kollmann, J. H. Chen, Dynamics of the flame surface area in turbulent non-premixed combustion, Symp. (Int.) on Combust. 25 (1994) 1990-1098.

[42] N. Peters, Local quenching due to flame stretch and non-premixed turbulent combustion, Combust. Sci. Technol. 30 (1983) 1-17.

[43] F. Dietzsch, A. Scholtissek, F. Hunger, C. Hasse, The impact of thermal diffusion on the structure of non-premixed flames, Combust. Flame 194 (2018) 352-362.

[44] D. G. Goodwin, H. K. Moffat, R. L. Speth, Cantera: An Object-oriented Software Toolkit for Chemical Kinetics, Thermodynamics, and Transport Processes. Version 2.3.0, http://www. cantera.org, 2017. doi:10.5281/zenodo.170284.

[45] A. Ern, V. Giovangigli, Multicomponent Transport Algorithms, Springer Berlin Heidelberg, 1994.

[46] A. Ern, V. Giovangigli, EGLIB: a General-Purpose Fortran Library for Multicomponent Transport Property Evaluation, Technical Report, CERMICS, 1996. 
[47] C. F. Curtiss, J. O. Hirschfelder, Transport properties of multicomponent gas mixtures, The Journal of Chemical Physics 17 (1949) 550-555.

[48] T. P. Coffee, J. M. Heimerl, Transport algorithms for premixed, laminar steady-state flames, Combust. Flame 43 (1981) 273-289.

[49] D. Bradley, P. H. Gaskell, X. J. Gu, Burning velocities, markstein lengths, and flame quenching for spherical methane-air flames: A computational study, Combust. Flame 104 (1996) 176-198.

[50] M. Baum, T. J. Poinsot, D. C. Haworth, N. Darabiha, Direct numerical simulation of $\mathrm{H}_{2} / \mathrm{O}_{2} / \mathrm{N}_{2}$ flames with complex chemistry in two-dimensional turbulent flows, J. Fluid Mech. 281 (1994) 1.

[51] M. Day, J. Bell, P.-T. Bremer, V. Pascucci, V. Beckner, M. Lijewski, Turbulence effects on cellular burning structures in lean premixed hydrogen flames, Combust. Flame 156 (2009) $1035-1045$.

[52] A. J. Aspden, M. S. Day, J. B. Bell, Turbulence-flame interactions in lean premixed hydrogen: transition to the distributed burning regime, J. Fluid Mech. 680 (2011) 287-320.

[53] B. Savard, G. Blanquart, Effects of dissipation rate and diffusion rate of the progress variable on local fuel burning rate in premixed turbulent flames, Combust. Flame 180 (2017) 77-87.

[54] C. K. Law, Combustion Physics, Cambridge University Press (CUP), 2006.

[55] J. F. Grcar, R. J. Kee, M. D. Smooke, J. A. Miller, A hybrid newton/time-integration procedure for the solution of steady, laminar, one-dimensional, premixed flames, Symp. (Int.) Combust. 21 (1988) $1773-1782$.

[56] A. Zschutschke, D. Messig, A. Scholtissek, C. Hasse, Universal Laminar Flame Solver (ULF), 2017. URL: https://www.doi.org/10.6084/m9.figshare.5119855.v2.

[57] T. Varga, T. Nagy, C. Olm, I. Zsély, R. Pálvölgyi, É. Valkó, G. Vincze, M. Cserháti, H. Curran, T. Turányi, Optimization of a hydrogen combustion mechanism using both direct and indirect measurements, Proc. Combust. Inst. 35 (2015) 589-596.

[58] G. P. Smith, D. M. Golden, M. Frenklach, N. W. Moriarty, B. Eiteneer, M. Goldenberg, C. T. Bowman, R. K. Hanson, S. Song, W. C. G. Jr., V. V. Lissianski, Z. Qin, Gri-mech 3.0, online, 1999. URL: http://www.me.berkeley.edu/gri_mech/.

[59] C. Olm, T. Varga, É. Valkó, S. Hartl, C. Hasse, T. Turányi, Development of an ethanol combustion mechanism based on a hierarchical optimization approach, Int. J. Chem. Kinet. 
48 (2016) 423-441.

[60] P. Domingo, L. Vervisch, D. Veynante, Large-eddy simulation of a lifted methane jet flame in a vitiated coflow, Combust. Flame 152 (2008) 415 - 432.

[61] E. Varea, V. Modica, A. Vandel, B. Renou, Measurement of laminar burning velocity and markstein length relative to fresh gases using a new postprocessing procedure: Application to laminar spherical flames for methane, ethanol and isooctane/air mixtures, Combust. Flame 159 (2012) 577-590.

[62] T. Poinsot, D. Veynante, Theoretical and Numerical Combustion, 3 ed., Cerfacs, 2012.

[63] R. J. Kee, J. A. Miller, G. H. Evans, G. Dixon-Lewis, A computational model of the structure and extinction of strained, opposed flow, premixed methane-air flames, Symp. (Int.) Combust. $22(1989) 1479-1494$.

[64] F. Egolfopoulos, H. Zhang, Z. Zhang, Wall effects on the propagation and extinction of steady, strained, laminar premixed flames, Combust. Flame 109 (1997) 237-252.

[65] J. Tien, M. Matalon, On the burning velocity of stretched flames, Combust. Flame 84 (1991) 238-248.

[66] C. Vagelopoulos, F. Egolfopoulos, C. Law, Further considerations on the determination of laminar flame speeds with the counterflow twin-flame technique, Symp. (Int.) Combust. 25 (1994) 1341-1347.

[67] P. Wang, J. A. Wehrmeyer, R. W. Pitz, Stretch rate of tubular premixed flames, Combust. Flame 145 (2006) $401-414$.

[68] S. Hu, P. Wang, R. W. Pitz, A structural study of premixed tubular flames, Proc. Combust. Inst. 32 (2009) 1133-1140.

[69] S. Balusamy, A. Cessou, B. Lecordier, Direct measurement of local instantaneous laminar burning velocity by a new PIV algorithm, Exp. Fluids 50 (2010) 1109-1121.

[70] E. Varea, J. Beeckmann, H. Pitsch, Z. Chen, B. Renou, Determination of burning velocities from spherically expanding $\mathrm{H}_{2}$ /air flames, Proc. Combust. Inst. 35 (2015) 711-719.

[71] Z. Chen, M. P. Burke, Y. Ju, Effects of lewis number and ignition energy on the determination of laminar flame speed using propagating spherical flames, Proc. Combust. Inst. 32 (2009) 1253-1260.

[72] J. Jayachandran, A. Lefebvre, R. Zhao, F. Halter, E. Varea, B. Renou, F. N. Egolfopoulos, 
A study of propagation of spherically expanding and counterflow laminar flames using direct measurements and numerical simulations, Proc. Combust. Inst. 35 (2015) 695-702. 